\title{
Hydrogel/Electrospun Fiber Composites Influence Neural Stem/Progenitor Cell Fate
}

\author{
by \\ Ming-Yi (Anne) Hsieh \\ A research report submitted in conformity with the requirements \\ for the degree of Masters of Applied Science \\ Graduate Department of Chemical Engineering and Applied Chemistry \\ Graduate Department of Biomaterial and Biomedical Engineering \\ University of Toronto
}

(C) Copyright by Ming-Yi (Anne) Hsieh 2009 


\title{
Hydrogel/Electrospun Fiber Composites Influence Neural Stem/Progenitor Cell Fate
}

Ming-Yi (Anne) Hsieh, Master of Applied Science and Engineering, 2009

Department of Chemical Engineering and Applied Chemistry, Institute of Biomaterial and Biomedical Engineering, University of Toronto

\begin{abstract}
Cell replacement therapy with multi-potent neural/stem progenitor cell into the injured spinal cord is limited by poor survival and host tissue integration. An injectable and biocompatible polymeric cell delivery system serves as a promising strategy to facilitate cell delivery, promote cell survival and direct cell behaviour. We developed and characterized the use of a physical hydrogel blend of hyaluronan and methylcellulose for NSPC delivery, and incorporated electrospun fibers of collagen or $\mathrm{P}(\mathrm{CL}: \mathrm{DLLA})$ to promote cell-matrix interactions and influence cell behaviour. HAMC was shown to be both cytocompatible and allow NSPC differentiation in vitro. Inclusion of electrospun fibers in the HAMC hydrogel further influenced cell behaviour. Composite systems of $\mathrm{P}(\mathrm{CL}: \mathrm{DLLA})$ fibers in HAMC maintained cell survival/proliferation and enhanced neuronal and oligodendrocytic differentiation similar to HAMC. The importance of the cell delivery vehicle to NSPC survival and cell fate was demonstrated in vitro and will be tested in on-going studies in vivo.
\end{abstract}




\section{ACKNOWLEDGEMENTS}

Two years of grad school has taught me many things.

I would like to thank my family in their full support to whatever decision I made. I would like to thank Dr. Molly Shoichet to be my supervisor in directing me through this project, and Drs. Morshead and Radisic to be my committee members to guide me through the last journey of the master defense.

Many thanks to my lab members, Ying (the always go to person, for everything in the lab since my first day in the lab), Jiao (to chat about the up and downs in lives), Tasneem, Howard, and Mike (for all cell related suggestions and support), Yukie (the late night chocolates), Ryan, Karyn, and Peter (you guys are just awesome! - the "insightful" discussion...), and Yuanfei (keeping me company in early mornings).

The two years has been a wonderful and fun experience. It is time for me to take a different route to try something new now! :; 


\section{Table of Contents}

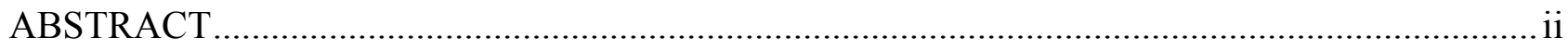

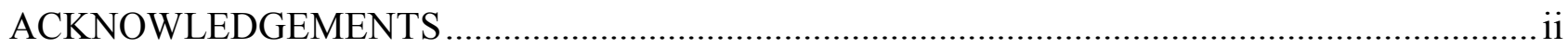

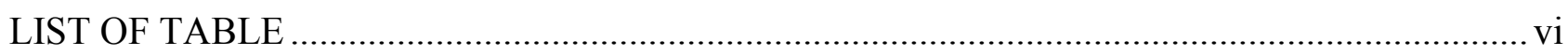

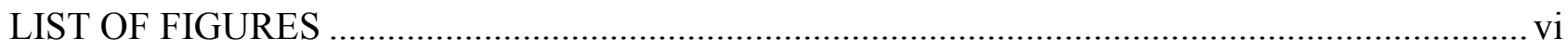

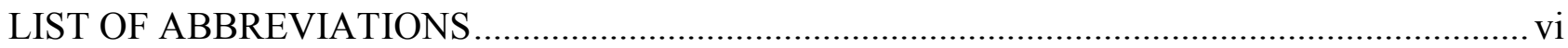

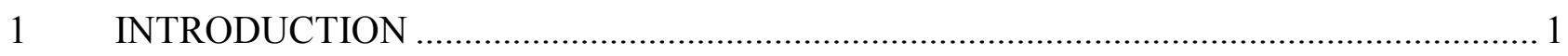

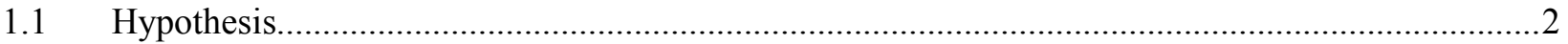

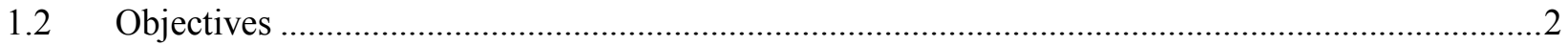

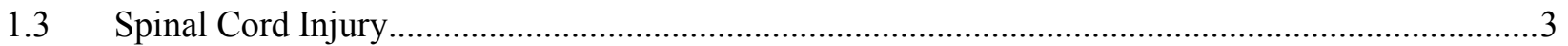

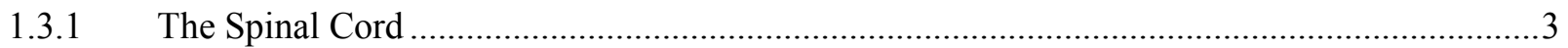

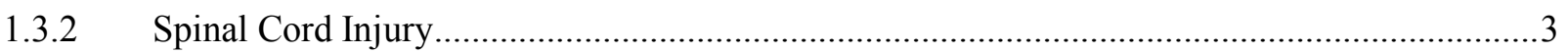

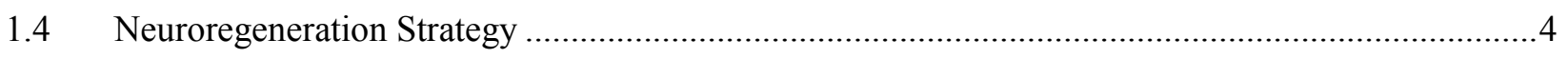

1.4.1 Cell-based therapy for SCI....................................................................................

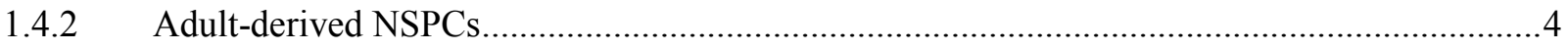

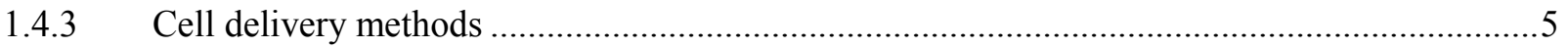

1.4.4 Current challenges in cell delivery ..............................................................................

1.4.5 Tissue engineering approach........................................................................................

1.4.6 Cell delivery vehicle and transplant device ………………………………………………..

1.4.7 Physical blend of HA and MC ………………………............................................

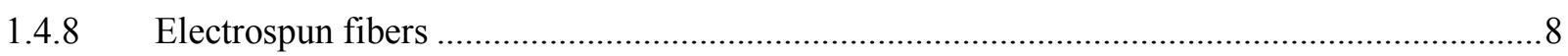

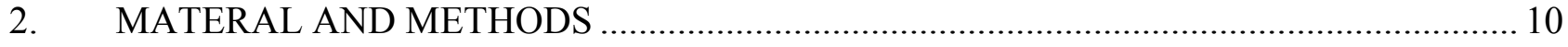

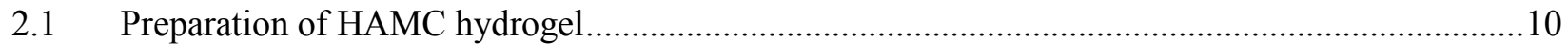

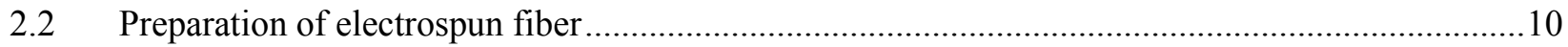

2.3 Mechanical testing and gelation time

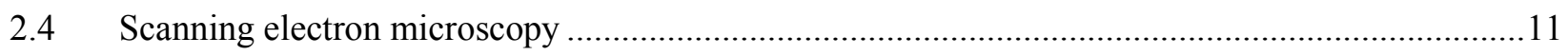

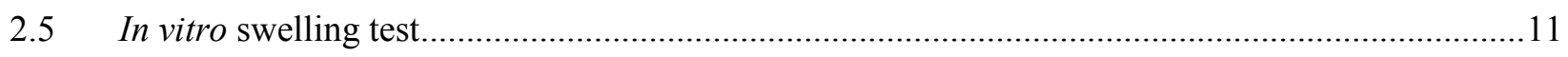

2.6 Neural stem/progenitor cell isolation and culture …………..................................................12

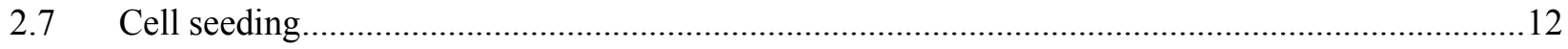

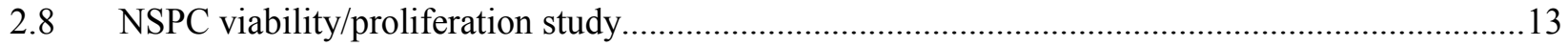

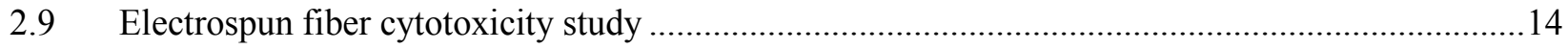

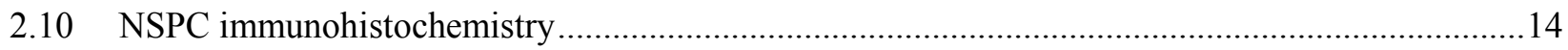




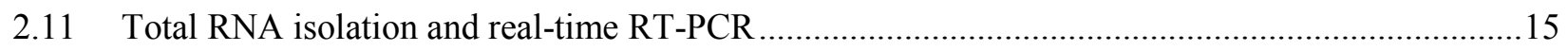

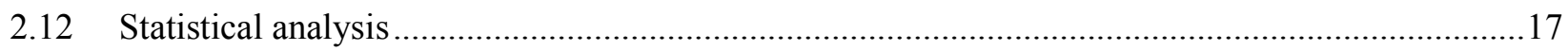

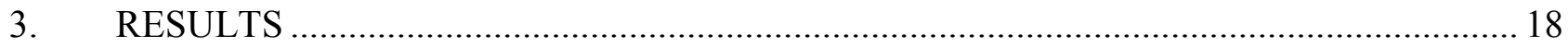

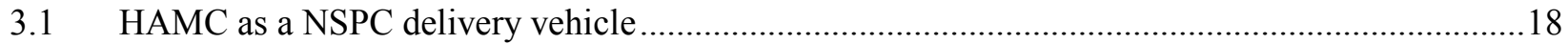

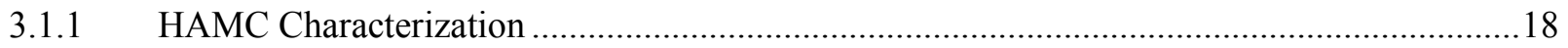

3.1.2 NSPCs cultured in HAMC vs. Media: Cell Distribution ......................................................19

3.1.3 NSPC viability and differentiation in HAMC vs. Media Controls .........................................21

3.2 NSPC viability and differentiation in electrospun fiber/HAMC composites...............................25

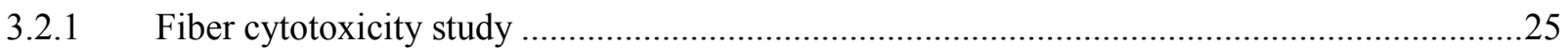

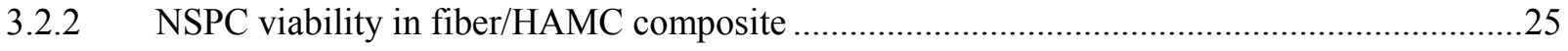

3.2.3 NSPC differentiation profile in fiber/HAMC composite .....................................................27

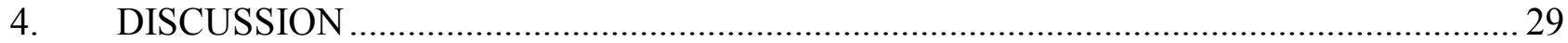

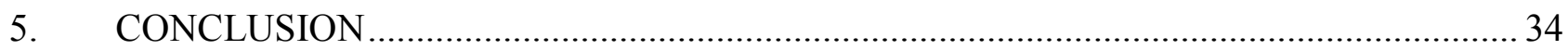

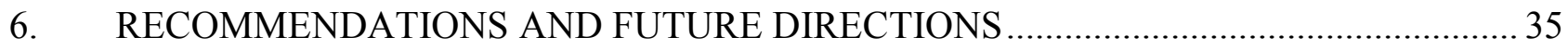

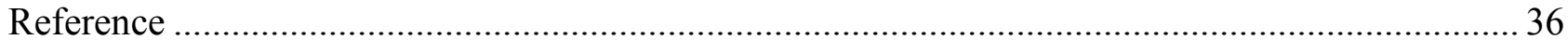




\section{LIST OF TABLE}

Table 1. Primer and probe designs for quantitative RT-PCR .16

\section{LIST OF FIGURES}

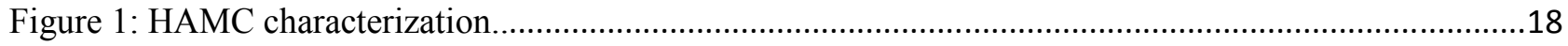

Figure 2: Bright-field microscopic images of NSPC neurosphere culture at day 2 ....................................20

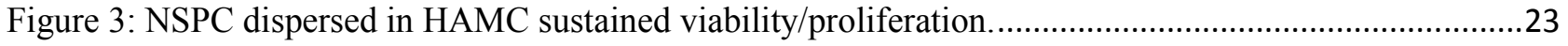

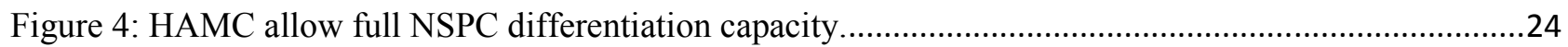

Figure 5: Electrospun fiber cytotoxicity study. NSPCs were cultured in fiber conditioned media for $7 \mathrm{~d}$.......25

Figure 6: Bright-field microscopy of NSPC seeded as single cells showing cellular responses and cell-matrix

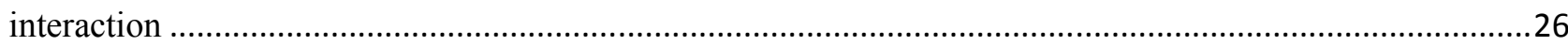

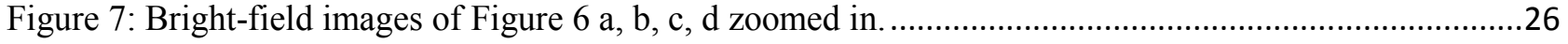

Figure 8: NSPC viability and differentiation profile in fiber/hydrogel composites after $7 \mathrm{~d}$. .......................29

\section{LIST OF ABBREVIATIONS}

ATP

BBB

CNPase

CNS

ECM

EGF

FBS

FGF

GFAP

HA

HPRT

$\mathrm{MC}$

$\mathrm{P}(\mathrm{CL}: \mathrm{DLLA})$

SCI

SEM

SVZ
Adenosine triphosphate

Beattie, Bresnahan, and Basso 21 point score scale for rat locomotion

2',3'-cyclic nucleotide 3'-phosphodiesterase

Central nervous system

Extracellular matrix

Epidermal growth factor

Fetal bovine serum

Fibroblast growth factor

Glial fibrillary acidic protein

Hyaluronan

Hypoxanthine phosphoribosyltransferase 1

Methylcellulose

Poly ( $\varepsilon$-caprolactone-co-D,L-lactide)

Spinal cord injury

Scanning electron microscope

Sub-ventricular zone 


\section{INTRODUCTION}

Spinal cord injury (SCI) from mechanical insult results in cell death and cavity formation, disrupting signalling pathways of the central nervous system (CNS) ${ }^{1}$. Patients often suffer lifetime sensory and motor deficits below the site of injury. Cell therapy is a promising strategy for tissue regeneration where, for example, neural stem/progenitor cells (NSPCs) have enhanced tissue repair and function after acute spinal cord injury ${ }^{2,3}$. NSPCs are multi-potent CNS cells capable of selfrenewal and terminal differentiation into neurons, oligodendrocytes, and astrocytes. However, poor graft survival and integration are major factors limiting the efficacy of cell transplantation therapy. After bolus injection of NSPCs into the spinal cord, significant cell death was observed ${ }^{3,4}$. Moreover, selective ablation of engrafted cells in the spinal cord reversed the locomotor improvement previously observed ${ }^{5}$. Thus major challenges for stem cell transplantation studies are cell survival and directed cell differentiation.

To enhance stem cell survival and differentiation, we focused on engineering the stem cell microenvironment using three-dimensional culture conditions. The choice of biomaterial, and its physical and chemical properties, influence cell differentiation ${ }^{6}$, survival ${ }^{7}$ and tissue integration ${ }^{8}$. Hydrogels are particularly compelling for cell delivery, having highly porous and hydrated structures that permit efficient diffusion of nutrients and oxygen, and metabolic waste products and $\mathrm{CO}_{2}$. The hydrogel can be tuned either chemically with adhesive and differentiation factors or physically through crosslinking, to yield a microenvironment that will influence cell proliferation and differentiation ${ }^{9-12}$. We were interested in testing hyaluronan (HA)-based hydrogels for cell delivery because HA is a naturally-derived polysaccharide in the extracellular matrix and has some wound healing properties on its own ${ }^{13}$. While HA alone does not form a gel, a physical blend of HA and methylcellulose (MC) forms a gel due to the thermally-reversible gelation properties of 
MC. ${ }^{14} \mathrm{MC}$ itself has also been studied after traumatic brain injury ${ }^{15}$. Importantly, HAMC has been shown to have some therapeutic benefit when delivered to the intrathecal cavity after spinal cord injury and can be injected using a minimally-invasive technique ${ }^{15-18}$.

Here we were interested in testing a HAMC formulation for cell delivery with and without the inclusion of electrospun fibers. Our hypothesis was that the electrospun fibers would provide a site for cell adhesion and thereby influence the differentiation profile of the stem/progenitor cells cultured within the fiber/hydrogel composite. We chose to compare the influence of naturallyderived collagen fibers vs. synthetic polymers of poly( $\varepsilon$-caprolactone-co-DL-lactide) vs. HAMC alone. For the latter, the in vitro biocompatibility of NSPCs dispersed in HAMC was evaluated by measuring the number of live cells and their metabolic activity in three media conditions, compared to media controls. The differentiation profile of the NSPCs in HAMC (with and without the fibers) was studied using immunocytochemistry and quantitative RT-PCR. In these series of studies, our goal was to evaluate the cellular response in vitro to the different culture conditions with a view of applying this knowledge to an in vivo system.

\subsection{Hypothesis}

A cell-loaded composite of HAMC and electrospun fibers will improve NSPC distribution throughout an injected volume while supporting cell survival and differentiation in culture.

\subsection{Objectives}

1. Develop and characterize an injectable, thermal-reversible hydrogel for NSPC.

Hydrogel's mechanical properties and cytocompatibility with NSPC will be assessed.

2. Incorporate and evaluate effects of electrospun fibers in hydrogel on NSPC behaviour NSPC viability/proliferation and gene expression profile will be examined. 


\subsection{Spinal Cord Injury}

\subsubsection{The Spinal Cord}

The spinal cord and the brain constitute the central nervous system (CNS) that coordinates the activities of all parts of the body and controls behaviour. The nervous tissue is primarily composed of three differentiated cell types - neurons, astrocytes, oligodendrocytes. Astrocytes and oligodendrocytes provide critical support for optima neuronal functioning, and neurons are the functional unit of the CNS, responsible for forming connections and are the communicating cells of the nervous system.

\subsubsection{Spinal Cord Injury}

Spinal cord injury (SCI) often result in cavity and cell death, disrupting the signalling pathway leading to loss of sensor and motor functions below the site of injury. Currently, there is no effective cure. Globally, 2.5 million people live with SCI, with more than 130,000 new cases reported every year ${ }^{19}$. Patients' suffer significant impacts on quality of life (paraplegia or quadriplegia) and economic burden (loss of income and requirement for long-term primary care).

To develop an effective strategy towards improved neuropreservation and neuroregenerative repair, understanding the neuropathophysiology of the traumatic SCI is essential. Compression injury as a result of the external mechanical insult from dislocation of spinal vertebral motion segments or displaced bone fragment is the most common injury model ${ }^{20}$. Following the initial trauma to the spinal cord, a series of events including vascular changes (edema, ischemia, and hypoxia), excitotoxic biochemical alternations (formation of free radicals and $\mathrm{NO}$ and protease release), and cellular response (immune cells, activation of glial cells, and apoptotic death of neurons and glia) causes progressive loss of neural tissue ${ }^{21}$. Cavities and cysts are formed interrupting descending and ascending axonal tracts ${ }^{22}$. 


\subsection{Neuroregeneration Strategy}

\subsubsection{Cell-based therapy for SCI}

Cell therapy to repair tissue and to restore function is a promising regenerative medicine modality. The main rationale for cell-based therapies following spinal cord injuries are: (1) replace degenerated spinal cord parenchyma by an axon growth supporting structure, to reconstruct the neuronal circuit as a relay bridge in the cavity; (2) remyelination of regenerating axons; and (3) produce and locally deliver neurochemically active substance to promote growth - trophic effect ${ }^{23}$.

Transplanted cells have the potential to replace tissue lost during trauma or to support the regeneration process. Cell types delivered for SCI injury include human embryonic stem cells (hESCs), fetal stem cells, mesenchymal stem cells, neural stem cells, ES-derived oligodendrocyte progenitor cells, olfactory ensheathing cells, Schwann cells, and macrophages ${ }^{23,24}$. Neural stem/progenitor cells (NSPCs) are of particular interest because of their capacity to differentiate into CNS cells, potentially becoming neurons to reconnect the signalling path or oligodendrocytes to remyelinate axons and producing growth factors.

\subsubsection{Adult-derived NSPCs}

The discovery of NSPCs by Reynold and Weiss ${ }^{25}$ opened the door to new therapeutic avenues for cell therapy in SCI. Subsequently, NSPCs have been characterized by adherent properties, proliferation kinetics, growth factor dependence, and gene expression ${ }^{2}$. In the adult mammal, NSPCs are located primarily in the sub-ventricular zone (SVZ) of the forebrain, in the sub-granular layer of the dentate gyrus of the hippocampal formation, and in the spinal cord ${ }^{2}$. They are multi-potent stem cells capable of self-renewal, and terminally differentiation into neurons and glial cells ${ }^{26}$. These intrinsic properties position NSPC as a promising candidate for cell-replacement therapy. 
However, the repair responses from injury-induced recruitment of endogenous NSPCs are impaired or limited shown by pathology. Strategies developed to facilitate mobilization of endogenous NSPC were reviewed by Okano et $\mathrm{al}^{27}$, an example including supplementation of exogenous growth factor ${ }^{28}$. The repair capacity of the endogenous NSPCs is under active research. In parallel, studies of transplantation of exogenous NSPCs have shown some success with partial functional recovery ${ }^{2}$.

\subsubsection{Cell delivery methods}

Route of cell administration is dependent on the type CNS lesion. While systemic (intravenous or intrathecal) transplantation is suitable for multifocal CNS disorder (e.g. multiple sclerosis), direct local (intralesional) cell transplantation is beneficial to focal CNS disorder (e.g. SCI, stroke $)^{26}$. Cell delivery for the compression SCI is either through the conventional bolus injection of cells suspended in liquid, or scaffolds/hydrogels implantation of cell seeded within.

\subsubsection{Current challenges in cell delivery}

NSPC survival, differentiation and integration are key requirements for an effective and efficient cell therapy. However, these conditions are generally not met. Parr and co-workers observed poor transplanted cell survival under optimized logistics, transplanting rat NSPC at subacute (9 d after compression SCI) model and $1 \mathrm{~mm}$ rostral and caudal to the injury site ${ }^{4}$. Another study by Karimi et al where mice NSPCs were transplanted 2 weeks post injury $2 \mathrm{~mm}$ rostral and caudal to the injury site combined with growth factors (EGF, FGF, and PDGF-AA), there was significant cell death 8 weeks after transplantation with partial functional recovery ${ }^{3}$. It is further indicated by Cummings et al that transplanted cell survival in the host is critical to maintain the functional recovery, where reversed locomotor improvement was observed with selective ablation of engrafted cell ${ }^{5}$. 
Once cell survival can be sustained post transplantation, the cells need to differentiate to become functional cells and to integrate with the host tissue. However, it has been found transplanted NSPCs tend to become astrocytes, the scar forming cells ${ }^{29}$, and integration is limited at the periphery of the lesion cavity, leaving the center of the cavity disconnected. The challenges led to inefficacious cell therapy aimed to restore function. Tissue engineering, an integration to regenerative medicine, has the potential to facilitate the process to deliver cells, to present cues to guide cell behaviour and to provide the missing structural support to bridge the lesion cavity.

\subsubsection{Tissue engineering approach}

NSPCs are highly responsive to environmental physical and chemical cues. Designing a microenvironment using biomaterials can promote efficient delivery and modulate spatial and temporal progression of the regenerative process commenced by cell transplantation.

For cell therapy to replace the lost tissue, the structure of the tissue should be reconstructed and integrated with the host. The application of scaffold or hydrogel can act as an infrastructure to support the transplanted cell. The integration of electrospun fibers may further provide cell-matrix interactions, collectively, with the goal to promote cell survival, and to direct cell differentiation. The influences of the engineered microenvironment to stem cell responses/activities such as morphology, adhesion, proliferation, and differentiation are of interest.

A minimally invasive cell delivery vehicle and transplantation device should meet the following design criteria. The biomaterial needs to be biocompatible to the host as well to the transplanted cells, supporting appropriate cellular activities. The system needs to be injectable through a needle and provide structural support to the transplanted cell in situ. The biomaterial should be biodegradable to allow integration of regenerated tissue to replace the implant. 


\subsubsection{Cell delivery vehicle and transplant device}

Among polymer scaffolds, hydrogels are attractive because of their highly porous and hydrated structure for efficient infusion of nutrients and oxygen and transfer of waste products and $\mathrm{CO}_{2}$ for cells. Biopolymers of alginate and poly(lactic-co-glycolic acid of natural and synthetic in origin, respectively, are reviewed by Hejcl et al where both of them supported axonal regeneration

across the lesion site ${ }^{30}$. Other hydrogels utilized for the NSPC include Pluronic 127 (non-ionic surfactant composed of a block copolymer of propylene oxide and ethylene oxide), matrigel (basal membrane extract derived from mouse sarcoma), and Puramatrix (ionic-self-complementary oligopeptides) where some toxicity and undefined content positioned them not suitable for translation to clinical settings ${ }^{31,32}$.

Composites of electrospun fiber in hydrogel have the potential to create a hospitable microenvironment for NSPCs, utilizing the well-hydrated 3D structure and sites for cell-matrix interaction, mimicking the natural ECM. Hence, we developed composites of collagen or $\mathrm{P}(\mathrm{CL}: \mathrm{DLLA})$ fibers in a hyaluronan and methylcellulose hydrogel and studied their effects with NSPCs.

\subsubsection{Physical blend of HA and MC}

An injectable hydrogel of hyaluronan (HA) and methylcellulose (MC) was developed that enables simple, efficient, reproducible and uniform seeding of viable NSPCs. The gel can be injected as fluid at room temperature and will gel in situ, conforming to the shape of the lesion cavity.

Hyaluronan is a high molecular weight and negatively charged glycosaminoglycan, composed of simple disaccharides of glucuronic acid and N-Acetylglucosamine with shear-thinning property $^{13}$. It is one of the major components in the extracellular matrix (ECM) that surrounds 
migrating and proliferating cells ${ }^{13}$, widely distributed throughout the CNS that regulate the maintenance of the stem cell population. HA has been shown to ensure the survival of the grafted stem cells while successive breakdown of the hyaluronan matrix release the contained cells to contribute to tissue regeneration ${ }^{33}$.

Methylcellulose is an anionic polymer, derived from cellulose, with reverse-thermal gelation property $^{14}$. The gelation is a kinetic process of hydrophobic interactions between methyl groups, with no involvement of chemical or photo crosslinking, minimizing inflammatory and toxicity response. It permits for microinjection of liquid form into a confined space and then gel in situ. It has been used as an injectable scaffold for the repair of defects in the brain, nerve gap, and SCI to promote nerve regeneration ${ }^{15,34,35}$.

\subsubsection{Electrospun fibers}

Electropinning can be used to produce scaffolds for tissue engineering. In the process, the polymer is dissolved in a solvent then ejected through a nozzle when electrostatic repulsive forces overcome the surface tension of the droplet at the syringe $\operatorname{tip}^{36}$. Fine fibers is produced at the droplet, solidified and deposited on a grounded metal collector. The nanofibrous structure of electrospun fibers with its diameters in magnitude mimics the fibrous proteins in ECM. The nanofeature of the fibers including diameter, orientation (alignment or random), nanotopography, charges, or hydrophobicity has the potential to influence cell activities ${ }^{37,38}$.

Collagen is the main fibrous protein connecting and supporting bodily tissues including skin, bone, tendons, and muscles ${ }^{39}$. It is inherently unstable in aqueous environment. Hence, genipin crosslinking is used to preserve structure and mechanical characteristics of the collagen fibrillar structure. NSPC progression from proliferation to neuronal differentiation and formation of functional synapses was reported for NSPC interdispersed in Type 1 collagen $^{40}$. 
Poly (e-caprolactone-co-D,L-lactide), $\mathrm{P}(\mathrm{CL}: \mathrm{DLLA})$, is a biodegradable and bioresordable material with many tissue engineering applications including nerve grafts ${ }^{41-43}$. It has also been studied for drug release ${ }^{44}$, and biomaterial microarray to screen cell responses ${ }^{45}$. 


\section{MATERAL AND METHODS}

\subsection{Preparation of HAMC hydrogel}

$\mathrm{HA}$ and $\mathrm{MC}$ were sterile-filtered as dilute aqueous solutions through $0.22 \mu \mathrm{m}$ vacuum filters (Nalgene, Rochester, NY, USA) and lyophilized prior to use. . HAMC $0.5 / 0.5$ was prepared with $0.5 \mathrm{wt} \%$ HA (Mw 1,500,000, Novamatrix, Norway) and $0.5 \mathrm{wt} \% \mathrm{MC}(\mathrm{Mw} 310,000$, ShinEtsu Metolose SM-4000, Japan) dissolved in one of three cell culture media: (1) Basic media: neurobasal media (Gibco-Invitrogen, Burlington, ON, Canada) supplemented with B27 neural supplement (Invitrogen), 2mM L-glutamine (Sigma-Aldrich, Oakville, ON, Canada) and $100 \mu \mathrm{g} / \mathrm{ml}$ penicillin-streptomycin (PenStrep; Sigma-Aldrich); (2) Differentiation media: basic media supplemented with 1\% fetal bovine serum (FBS) (Invitrogen); (3) Proliferation media: basic media supplemented with $20 \mathrm{ng} / \mathrm{ml}$ epidermal growth factor (recombinant human EGF; Invitrogen), 20 $\mathrm{ng} / \mathrm{ml}$ basic fibroblast growth factor (recombinant human bFGF; Invitrogen) and $2 \mu \mathrm{g} / \mathrm{ml}$ heparin (Sigma-Aldrich).

\subsection{Preparation of electrospun fiber}

Electrospun fibers of genipin crosslinked collagen and poly(e-caprolactone-co-D,L-lactide) (PCL:DLLA)fibers were prepared as previously described, with average diameters of $200 \mathrm{~nm}$ and $900 \mathrm{~nm}$, respectively. The collagen fibers were disinfected by immersion in $70 \%$ ethanol for one day whereas the PCL:DLLA fibers were sterilized by gamma irradiation (Co-60, 2.5mRad). The fibers were washed ( 3 times, $2 \mathrm{~h}$ each time) in basic media and then sonicated (Sonics Vibra Cell CV18 tip sonicator) twice consecutively for $30 \mathrm{~s}$ at $20 \mathrm{kHz}, 25 \%$ amplitude. The resulting fiber fragments were easily incorporated into the HAMC which was still injectable through the fine 30 gauge needle. For each study, there were $5 \mathrm{mg} / \mathrm{ml}$ of electrospun fibers dispersed cell culture medium. 


\subsection{Mechanical testing and gelation time}

Rheological evaluation: The rheological properties of HAMC were characterized by a stresscontrolled steady state experiment at $25{ }^{\circ} \mathrm{C}$ and $37{ }^{\circ} \mathrm{C}$ using an AR2000 rheometer (TA Instruments, New Castle, DE, USA) equipped with a $60-\mathrm{mm}, 0.5^{\circ}$ cone. To allow thermal equilibration to occur, all samples were conditioned for 20 min prior to shear. Measurements were then performed at shear stresses ranging between 0.01 and $80 \mathrm{~Pa}$ at both $25^{\circ} \mathrm{C}$ and $37^{\circ} \mathrm{C}$.

Inverted tube test: $300 \mu \mathrm{HAMC}$ made in basic medium was injected into the bottom of a $1.7 \mathrm{ml}$ microcentrifuge tube (Fisher Scientific, Ottawa, ON, CA) and incubated at $37{ }^{\circ} \mathrm{C}$. At 5,10 , $12,14,16,18,20 \mathrm{~min}$. intervals, tubes were inverted to observe if the gel flowed. The time at which the gel did not flow was recorded as the gelation time.

\subsection{Scanning electron microscopy}

To prepare HAMCM for scanning electron microscopy (SEM), the hydrogel was snap frozen and freeze dried under vacuum, then sputter coated with gold (Desk II, Denton Vacuum Moorestown). Samples were imaged using XL130 (FEI company, Hillsboro Oregon) with an acceleration voltage of $20 \mathrm{kV}$.

\subsection{In vitro swelling test}

$100 \mu 1$ of $0.5 / 0.5 \mathrm{w} / \mathrm{w} \%$ HAMC made in media was added to a $1.7 \mathrm{ml}$ eppendorf tube that was equilibrated at $37^{\circ} \mathrm{C}$. On the top of the gel, $900 \mu \mathrm{l}$ of $37^{\circ} \mathrm{C}$ artificial cerebrospinal fluid (aCSF): $0.5 \mathrm{mM} \mathrm{NaCl}, 5 \mathrm{mM} \mathrm{KCl}, 1.3 \mathrm{mM} \mathrm{MgCl} 2,0.1 \mathrm{mM} \mathrm{CaCl}_{2}, 26 \mathrm{mM} \mathrm{NaHCO}_{3}$, and $10 \mathrm{mM} \mathrm{D}-$ glucose, $\mathrm{pH}$ 7.4, was added. , Post set-up, half of the media was removed from the tubes every 24 $\mathrm{hr}$ and exchanged with fresh incubation media. To study the trend transiently, samples were collected at each time point. At $0,8 \mathrm{~h}, 1,3,6,9$ days of incubation, all the media was removed and 
the weight of the wet gel was recorded $(n=4)$. The polymer samples were snap frozen and dried using the freeze dryer, and the remaining polymer mass was weighed. Swelling was quantified as a function of time. The swelling value is given by the wet gel weight at each time point divided by that of time zero and multiplied by $100 \%$.

\subsection{Neural stem/progenitor cell isolation and culture}

Neural stem/progenitor cells were isolated from the subependyma of the lateral ventricles of adult female Wistar rat forebrains, as described previously ${ }^{19}$. Briefly, subependymal tissue was harvested from 8-12 week old rats and dissociated with papain (Papain Dissociation System; Worthington Biochemcial Corporation, Lakewood, NJ, USA). The resultant cell suspension was centrifuged and the pelleted cells were subjected to a discontinuous density gradient to remove cell debris. Dissociated cells were re-suspended in proliferation media. The cells were incubated at $37{ }^{\circ} \mathrm{C}$ in a humidified incubator with 5\% $\mathrm{CO}_{2}$. Neurospheres appeared in 2-3 weeks, after which cells were passaged every week. All cell studies used neurospheres at passages 4 and 5 .

\subsection{Cell seeding}

Neurospheres were centrifuged and washed once in basic media. A small sample of neurospheres were triturated into single cells and counted with a hemacytometer using trypan blue (Sigma-Aldrich) exclusion to determine the starting live cell population. Neurospheres were cultured for $4 \mathrm{~d}$ in the in vitro biocompatibility study because, after $4 \mathrm{~d}$, there was significant aggregation of neurospheres in the proliferation media, which made the results difficult to interpret. Dissociated single cells were cultured for $7 \mathrm{~d}$ for the differentiation profile studies. $2 \times 10^{4}$ NSPCs were dispersed in $100 \mu \mathrm{l}$ of either: media alone, HAMC, electrospun collagen fiber/HAMC or electrospun PCL:DLLA/HAMC and then loaded into $1 \mathrm{ml}$ syringes and injected through 30G, 1" needle into black clear-bottom 96-well plates (Greiner, Germany). $200 \mu$ l of media was added on 
day 3 to supply nutrients in the $7 \mathrm{~d}$ cultures. Cells were imaged on an inverted microscope (Axiovert S100, Zeiss) equipped with a camera (Cool SNAP HQ, Photometrics) on day 2 and 7.

\subsection{NSPC viability/proliferation study}

Quant-iT $^{\text {TM }}$ PicoGreen ${ }^{\circledR}$ dsDNA Kits: NSPCs were collected from cell culture wells into a $1.7 \mathrm{ml}$ eppendorf tube, spun down at $3000 \mathrm{rpm}$ for $5 \mathrm{~min}$., and washed once in sterile PBS. NSPCs were lysed through a freeze-thaw cycle in $1 \mathrm{X}$ Tris-EDTA buffer and 0.2\% Triton X-100 (SigmaAldrich). Total double stranded DNA was measured by fluorescence (Molecular Devices) by the reaction of DNA with PicoGreen (PicoGreen dsDNA Quantitation Kit; Invitrogen). An internal standard curve was prepared and used to convert the concentration of dsDNA to total number of cells. The data were expressed as fold growth relative to number of NSPCs seeded.

CellTiter-Glo Luminesent Cell Viability Assay: CellTiter-Glo Luminescent Cell Viability Assay (Promega, Madison, WI, USA) quantifies the cytoplasmic Adenosine Triphosphate (ATP) present, an indicator of metabolically active cells. It results in cell lysis and generates a luminescent signal proportional to the total amount of ATP present in the viable cells. $100 \mu$ l of CellTiter-Glo reagent was added to the culture well and placed on a rotary shaker plate for 10 min in the dark. Luminescence was recorded immediately after using a SpectraMax Gemini EM microtiter plate reader (Molecular Devices Corporation, Sunnyvale, CA, USA). The mean background luminescent signals from the media and cell-free HAMC controls were subtracted from the luminescence signals from the NSPCs in media and HAMC samples, respectively.

LIVE/DEAD ${ }^{\circledR}$ Viability/Cytotoxicity Assay: Cell viability was quantitatively assessed with a Live/Dead kit (Molecular Probes; Eugene, OR). To prepare the cells, the cells was collected in a $1.7 \mathrm{ml}$ eppendorf tube, spun down at $3000 \mathrm{rpm}$ for $5 \mathrm{~min}$ and then the supernatant removed. The 
cell pellet was then resuspended in sterile PBS with $2 \mu \mathrm{M}$ calcein-AM (a live cell fluorescent dye, $485 / 530 \mathrm{~nm}$ ) or $10 \mu \mathrm{M}$ ethidium homodimer (a dead cell fluorescent dye, 530/645nm).

\subsection{Electrospun fiber cytotoxicity study}

Electrospun fibers of genipin crosslinked collagen and $\mathrm{P}(\mathrm{CL}-\mathrm{co}$-DLLA) were placed in culture inserts $(0.4 \mu \mathrm{m}, \mathrm{BD}$ Biosciences, Fanklin Lakes, NJ, USA) and immersed in NBM, incubated at $37^{\circ} \mathrm{C}$ and $5 \% \mathrm{CO}_{2}$ for 7 days. The conditioned media was then used to culture NSPCs at a density of $2 \times 10^{4}$ single cells/100 $\mu$ f for 7 days. Cell viability was examined using PicoGreen and CellTiter-Glo assays, as described above.

\subsection{NSPC immunohistochemistry}

Cryostat sectioning: Single cell cultures of $2 \times 10^{4}$ single cells/100 $\mu$ of HAMC were grown for $7 \mathrm{~d}$ in the differentiation medium. Cryomatrix (Thermo Scientific, Pittsburgh, USA) was added to the well and placed at room temperature for $5 \mathrm{~min}$, then snap frozen. $20 \mu \mathrm{m}$ sections were cut using cryotome (Leica CM3050, Bensheim, Germany), and mounted on glass slides.

Immunostainning: The following primary antibodies were used for immunohistochemistry (IHC): monoclonal mouse anti- $\beta$-III tubulin (1:1000; Abcam, Cambridge, MA, USA) for neurons; RIP monoclonal anti-2',3'-cyclic nucleotide 3'-phosphodiesterase (CNPase) (1:5; Developmental Studies Hybridoma Bank, Iowa City, IA, USA) for oligodendrocytes; monoclonal mouse anti-glial fibrillary acidic protein (GFAP, 1:100; Cell Sciences, Canton, MA, USA) for astrocytes; and monoclonal mouse anti-nestin (1:500; BD Biosciences, San Jose, CA, USA) for progenitor cells. Cells were fixed after 7 days of culture with PBS solution containing 4\% paraformaldehyde (Sigma-Aldrich) for $20 \mathrm{~min}$ at room temperature and then washed with PBS 3 times. Cell membranes were permeabilized with $0.1 \%$ Triton X-100 in PBS for 10 min., washed 3 times, then 
blocked with a solution of $10 \%$ FBS in PBS at room temperature for $1 \mathrm{~h}$. Next, each primary antibody solution was added for $2.5 \mathrm{~h}$ at $25^{\circ} \mathrm{C}$. After washing with PBS 3 times, samples were exposed to goat anti-mouse IgG Alexa-Fluor 546 (1:400; Invitrogen) for $2 \mathrm{~h}$ at room temperature and then washed with PBS buffer 3 times. Finally, cell nuclei were counterstained with $10 \mu \mathrm{M}$ Hoechst 33342 (Invitrogen) for $7 \mathrm{~min}$, washed with PBS buffer and mounted/coverslipped using ProLong Gold anti-fade reagent (Invitrogen). Fluorescent signals were detected and imaged via confocal laser scanning microscopy (Olympus BX61, Ontario, Canada) equipped with a camera (Olympus DP70).

\subsection{Total RNA isolation and real-time RT-PCR}

To monitor the expression level of differentiation gene markers using qRT-PCR, total RNA from the cells was prepared. Cells were collected at day 7 into $2 \mathrm{ml} \mathrm{screw-cap} \mathrm{microvials} \mathrm{with} 1.0 \mathrm{~mm}$ Zirconia Beads (BioSpec Products, Bartlesville, OK, USA), and homogenized using minibeadbeater-16 (BioSpec Products) for $3 \mathrm{~min}$. Total RNA was isolated using the acid guanidinum thiocyanate-phenol-chloroform extraction method, with $1 \mathrm{ml}$ Trizol reagent (Invitrogen) and $0.2 \mathrm{M}$ potassium acetate to remove the polysaccharide (HAMC) from the sample before adding chloroform for RNA extraction.

After RNA isolation, DNase I treatment was performed followed by the measurement of total RNA concentration and purity (NanoDrop ND-1000). For the reverse transcription (RT) reaction, $15.7 \mu \mathrm{L}$ of RNA (at $5 \mathrm{ng}$ total $\mathrm{RNA} / \mu \mathrm{L}$ ) was incubated with oligo(dT) primers and random hexamers at $65{ }^{\circ} \mathrm{C}$ for $5 \mathrm{~min}$. After cooling to room temperature, the RNAoligo(dT)/hexamer mix, buffer, dNTPs, RNase inhibitor, Stratagene AffinityScript RT enzyme (La Jolla, CA, USA) for $60 \mathrm{~min}$ at $42{ }^{\circ} \mathrm{C}$. The reaction was terminated by $70{ }^{\circ} \mathrm{C}$ for $15 \mathrm{~min}$. Quantitative reverse transcriptase-polymerase chain reaction (qRT-PCR) amplification was 
performed with a Roche LightCycler ${ }^{\circledR} 480$ (Laval, Quebec, Canada) using SYBR Green I (Invitrogen) detection chemistry. The 5' to $3^{\prime}$ sequences for the forward primers and reverse primers were previously designed in our lab from rat mRNA sequences from the National Center for Biotechnology Information (NCBI) given in Table 1. For qRT-PCR analysis of each sample, the following were prepared in a $11 \mu \mathrm{L}$ reaction buffer: $1 \mu \mathrm{L}$ of DNA sample, buffer, 3-4 $\mathrm{mM} \mathrm{MgCl}_{2}$, 0.2 mM DNTPs, 200-400 nM of each forward and reverse primer, 0.5X SYBR Green I, 1X ROX reference dye (Sigma-Aldrich), and $0.055 \mathrm{U}$ HotStarTaq (Qiagen, Valencia, CA, USA). Quantitative RT-PCR amplification was achieved with a 15 min activation step at $95{ }^{\circ} \mathrm{C}$, followed by 50 cycles of $15 \mathrm{~s}$ at $94{ }^{\circ} \mathrm{C}, 30 \mathrm{~s}$ at $60{ }^{\circ} \mathrm{C}, 60 \mathrm{~s}$ at $72{ }^{\circ} \mathrm{C}$ and a fluorescence measurement (excitation/emission $-494 / 521 \mathrm{~nm}$ ). All qRT-PCR reactions were performed in triplicate. A standard curve (cycle threshold value versus relative template concentration) was prepared for each target gene and for the endogenous reference (HPRT). Gene expression for each target gene was compared across experimental groups, and the relative fold change was calculated by normalizing against the endogenous reference genes using Pfaffl's efficiency corrected calculation model for multiple reference genes. Primer sets were used shown in Table 1.

Table 1. Primer and probe designs for quantitative RT-PCR

\begin{tabular}{l|l}
\hline \hline Gene* & $\begin{array}{l}\text { Forward Primer } \\
\text { Reverse Primer }\end{array}$ \\
\hline $\begin{array}{l}\text { Hypoxanthine phosphoribosyltransferase 1 } \\
\text { (HPRT) }\end{array}$ & $\begin{array}{l}\text { CTCATGGACTGATTATGGACAGGAC } \\
\text { GCAGGTCAGCAAAGAACTTATAGCC }\end{array}$ \\
\hline$\beta$ III tubulin & $\begin{array}{l}\text { ACTTTATCTTCGGTCAGAGTG } \\
\text { CTCACGACATCCAGGACTGA }\end{array}$ \\
\hline $2^{\prime}, 3^{\prime}$-cyclic nucleotide 3'-phosphodiesterase \\
(CNPase) & CAACAGGATGTGGTGAGGA \\
\hline Glial fibrillary acidic protein & CTGTCTTGGGTGTCACAAAG \\
(GFAP) & GAGAGAGATTCGCACTCAGTA \\
\hline \multirow{2}{*}{ Nestin } & TGAGGTCTGCAAACTTGGAC \\
\hline
\end{tabular}

*All sequences are 5'- 3' 


\subsection{Statistical analysis}

All statistical analyses were performed using JMP IN 7.1 (SAS Institute, Cary, NC, USA). Differences among groups were assessed by ANOVA with Tukey's post hoc analysis to identify statistical differences among three or more treatments. All errors are given as standard deviation. 


\section{RESULTS}

\subsection{HAMC as a NSPC delivery vehicle}

\subsubsection{HAMC Characterization}

The $0.5 / 0.5 \mathrm{w} / \mathrm{w} \%$ HAMC hydrogel was characterized by SEM, time to gelation, viscosity, rheology and swelling (Figure 1). As shown by SEM of the freeze-dried sample, HAMC is a porous structure with pores on the order of 20 to $50 \mu \mathrm{m}$ (Figure 1a). By the inverted tube test, HAMC gells after 18 min at $37^{\circ} \mathrm{C}$.
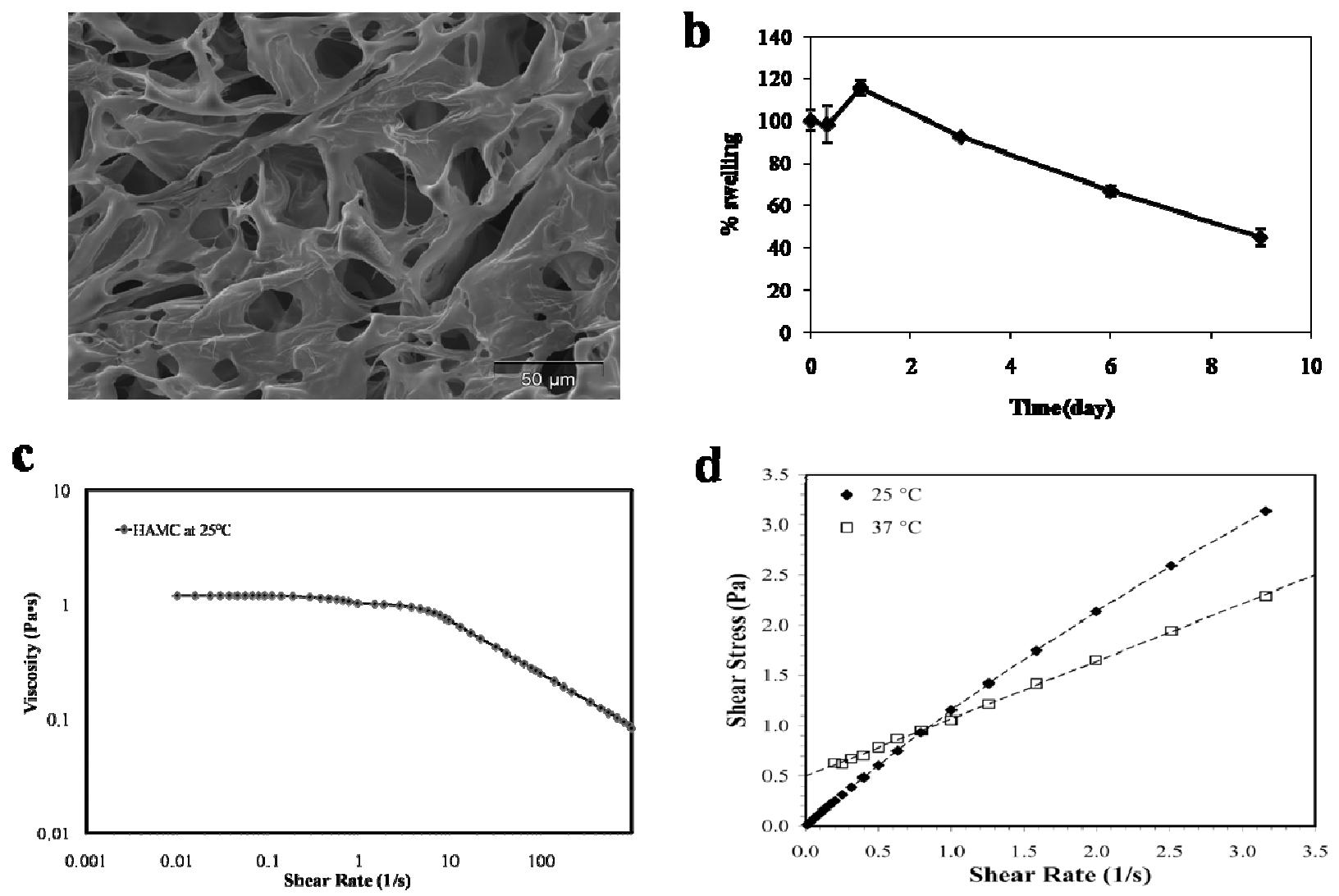

Figure 1: HAMC characterization. (a) SEM of HAMC (250\% magnification); (b) swelling; (c) viscosity vs. shear rate, demonstrating shear-thinning (d) shear stress vs. shear rate, demonstrating a yield stress at $37^{\circ} \mathrm{C}$ 
The shear stress $(\tau)$ vs. shear rate $(\gamma)$ data in the limit of low shear rate for HAMC at both 25 and $37^{\circ} \mathrm{C}$ are illustrated in Figure $1 \mathrm{~d}$. At $25^{\circ} \mathrm{C}$, HAMC displays nearly-Newtonian behaviour - that is a linear shear stress vs. shear rate relationship without a yield stress, where $(\tau=\eta \bullet \gamma)$, reflecting the nearly constant viscosity in the low-shear portion of the flow curve. At $37^{\circ} \mathrm{C}$, however, a yield stress of $0.5 \mathrm{~Pa}$ is observed. Thus, the blend exhibits nearly perfect Bingham plastic behaviour, according to $\tau=\mu_{\mathrm{p}} \bullet \gamma+\tau_{\mathrm{y}}$, where $\mu_{\mathrm{p}}$ is the plastic viscosity of approximately $0.6 \mathrm{~Pa} \cdot \mathrm{s}$ and a yield stress of $0.5 \mathrm{~Pa}$, which corresponds to the formation of a very weak gel.

To gain greater insight into the injectability of HAMC at the $0.5 / 0.5 \mathrm{w} / \mathrm{w} \%$ composition, its viscosity at room temperature was characterized over a broader range of shear rates. At room temperature $\left(25^{\circ} \mathrm{C}\right), \mathrm{HAMC}$ is a moderately-viscous solution with shear thinning properties (Figure 1c). This rheological signature is characteristic for polymeric blends, where the viscosity, $\eta$, remains nearly constant $(\eta=1.2 \mathrm{~Pa} \bullet \mathrm{s})$ at low shear rates and decreases with a power law relationship at high shear rates, and in this case, with a scaling exponent of $\sim 0.5$.

Since HAMC is designed to be injected into a tissue cavity, the degree of gel swelling was investigated to ensure minimal tissue damage such as compression of the soft tissue at the injured site. The swelling of HAMC reached a maximum swollen volume of approximately $115 \%$ by 1 day and gradually decrease to $50 \%$ by day 9 (Figure $1 \mathrm{~b}$ ).

\subsubsection{NSPCs cultured in HAMC vs. Media: Cell Distribution}

NSPCs cultured in media were compared to those cultured in HAMC in terms of cell distribution over time. As shown in bright-field images (Figure 2), NSPC neurospheres cultured in differentiation media of EGF/FGF2/heparin alone aggregated (Fig 2a) whereas those cultured in differentiation media in HAMC remained dispersed in the gel (Fig 2b). The aggregated neurospheres cultured in media had darkened necrotic cores unlike those cultured in media in 
HAMC. In differentiation media of $1 \%$ FBS, NSPC neurospheres displayed different morphologies when cultured in media vs. HAMC. Interestingly, there was little evidence of differentiation after $48 \mathrm{~h}$ of NSPCs cultured in differentiation media, where the cell body remained spherical (Fig 2c). In contrast, NSPCs cultured in differentiation media in HAMC extended processes and formed networks (Fig 2d).

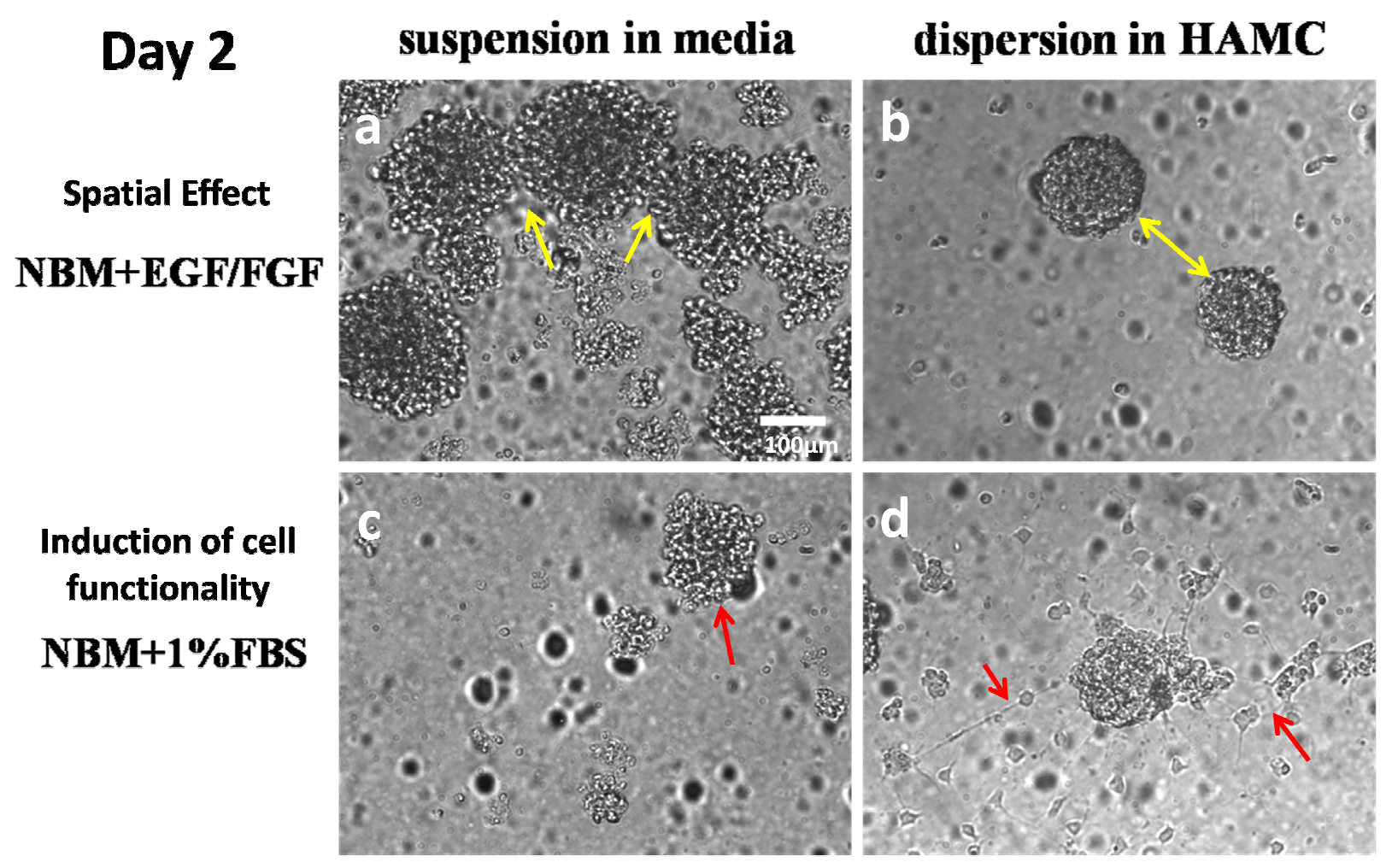

Figure 2: Bright-field microscopic images of NSPC neurosphere culture at day 2. HAMC's (a) cells cultured in proliferation media aggregated whereas those cultured in (b) proliferation media in HAMC remained dispersed throughout the gel. (c) NSPC neurospheres cultured in differentiation media remained spherical whereas (d) NSPC neurospheres cultured in differentiation media in HAMC extended processes and formed networks with other neurospheres. Arrows highlight processes and morphological changes of NSPCs in (d). The scale bar is $100 \mu \mathrm{m}$. 


\subsubsection{NSPC viability and differentiation in HAMC vs. Media Controls}

The number of NSPCs cultured in HAMC was compared to those in media after 4 days of culture where dsDNA content by the Picogreen assay was used as a proxy for cell number. Importantly, cells cultured in HAMC were injected via a 30-gauge needle into the culture well, thereby simulating the in vivo injection procedure. The day 4 data was normalized to day 0 to account for any variability in the number of NSPCs seeded. The number of NSPCs cultured in media was comparable to those dispersed in HAMC (Fig 3a). In basic culture conditions, there were more live cells in HAMC relative to the media control. While there were no other differences observed among cells grown in media vs. HAMC for the other media conditions, NSPCs grew more rapidly when cultured in the presence of mitogens (EGF/FGF2) than the basal and differentiation media conditions.

To assess the metabolic activity of NSPCs in different culture conditions, total cellular plasma ATP was measured using the luminescence assay (Fig 3b). No difference was found of cells cultured in basal or differentiation media conditions; however, cells cultured in the EGF/FGF2 proliferation media had higher ATP content per live cell. Interestingly, cells cultured in this proliferation media in HAMC had a lower luminescent signal, and thus less ATP/live cell, than cells cultured in just the proliferation media. We further conducted a small study, culturing NSPCs in the three media and measuring their ATP content per live cell. The same trend was verified, with higher ATP content of proliferating cells in EGF/FGF supplemented media (data not shown).

To gain a thorough understanding of how the culture environment affected cell viability, the percentage of live cells, by calcein AM staining, and the percentage of dead cells, by ethidium bromide homodimer, were measured (Fig 3c, 3d). The percentage of live cells was similar for NSPCs cultured in neurobasal or differentiation media with and without HAMC. However, the 
percentage of live cells was lower in the proliferation media, whether cultured in HAMC or media, relative to the basal and differentiation media. Interestingly, there were more live cells in HAMC than media controls. Thus, while the PicoGreen data for dsDNA (Fig 3a) showed greater numbers of cells in the proliferation media, the percentage of live cells was lower in the proliferation media than the other media conditions and HAMC, which is consistent with the brightfield microscopic images of Figure 2. The percentage of dead cells data was consistent with the percentage of live cells data. There was no difference in the percentage of dead cells in the basal or differentiation media for cells cultured in media or HAMC; however, there was a higher percentage of dead cells cultured in the proliferation media relative to the basal and differentiation media conditions. Moreover, there were more dead cells cultured in proliferation media than proliferation media in HAMC. These data are consistent with having necrotic cores in the neurospheres cultured in proliferation media alone vs. those in HAMC.
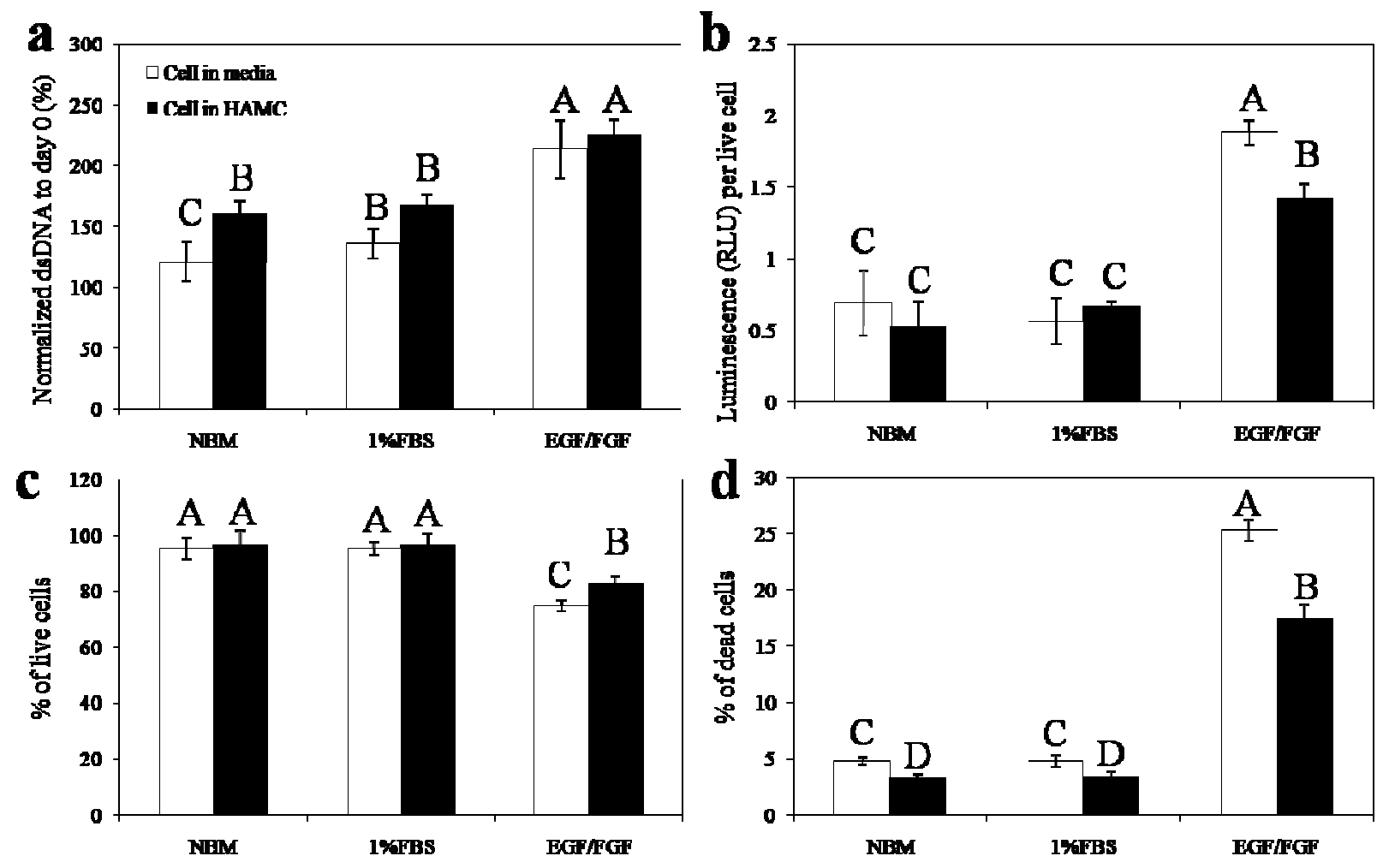
Figure 3: NSPC neurospheres cultured in different media alone vs. different media in HAMC after 4 days; (a) The PicoGreen assay for dsDNA shows greater number of cells in the proliferation, EGF/FGF2, media and comparable numbers for cells cultured in media or HAMC; (b) CellTiter Glo luminescence assay for ATP shows greater ATP content per cell for cells cultured in the proliferation media than in basal and differentiation media conditions. Within the same media condition, cellular metabolic activity in HAMC was comparable to media controls in basal and differentiation conditions; however, the ATP content per live cell was higher in the in the proliferation media control vs. HAMC. (c) By calcein AM, the percentage of live cells was similar for basal and 1\% FBS differentiation media, yet lower in the proliferation media, where there was a lower percentage of live cells in media vs. HAMC. (d) By ethidium homodimer, the percentage of dead cells was lower in HAMC than media controls for all media conditions. Of the media conditions, the percentage of dead cells was greater in the proliferation media. (mean \pm standard deviation are shown for $\mathrm{n}=3$; different letters indicate significant differences at $\mathrm{p}<0.05$ ).

NSPCs have been previously shown to differentiate to neurons, oligodendrocytes and astrocytes when cultured in 1\% FBS-supplemented media. To ensure that NSPCs maintain this differentiation capacity when cultured in HAMC, the cells were characterized by immunohistochemistry after $7 \mathrm{~d}$ of culture. Fluorescent microscopy showed cells stained positive for: BIII-tubulin for neurons (Fig 4a); GFAP for astrocytes (Fig 4b); RIP for oligodendrocytes (Fig 4c); and nestin for neural precursor cells (Fig 4d). These data demonstrate that HAMC impacts neither the differentiation capacity of NSPCs to neurons, astrocytes, and oligodendrocytes nor the presence of the precursor population. 


\section{a. BIII (neurons)}

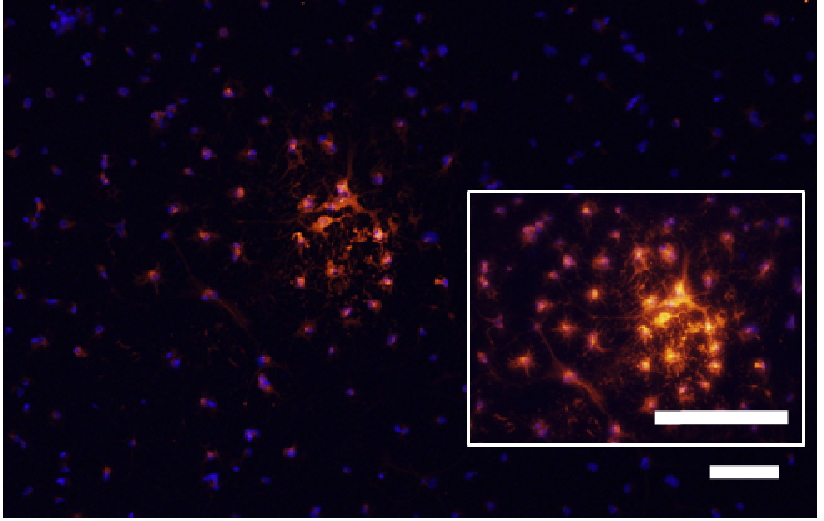

\section{c. RIP (oligodendrocytes)}

\section{b. GFAP (astrocytes)}

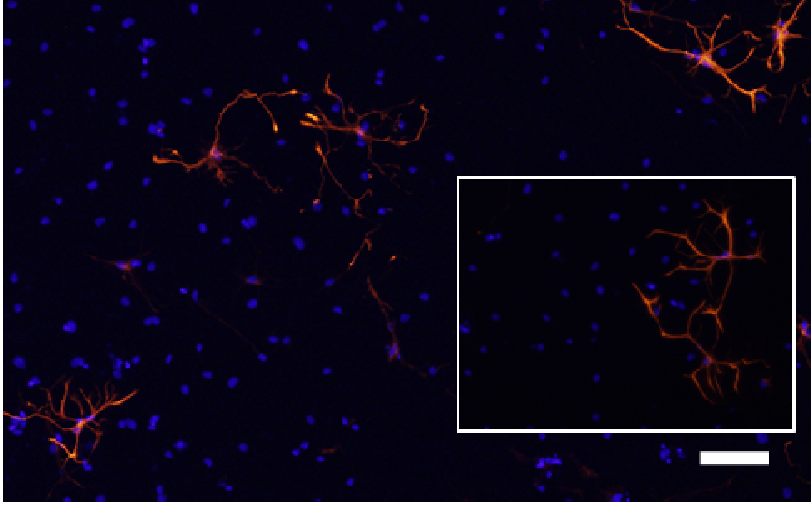

\section{d. Nestin (progenitor cells)}

Figure 4: NSPCs cultured in HAMC in 1\% FBS media for $7 \mathrm{~d}$ differentiated to: (a) $\beta$ III-tubulinpositive neurons; (b) GFAP-positive astrocytes; (c) RIP-positive oligodendrocytes; and (d) nestinpositive progenitor cells. Cell nuclei were stained with Hoechst shown in blue. Scale bar is $200 \mu \mathrm{m}$. 


\subsection{NSPC viability and differentiation in electrospun fiber/HAMC composites}

\subsubsection{Fiber cytotoxicity study}

Prior to testing NSPCs in the composite system, the P(CL-co-DLLA) and collagen electrospun fibers were independently screened for cytotoxicity. The fibers were separately immersed for $7 \mathrm{~d}$ in the basic media that was used to then culture NSPCs for $4 \mathrm{~d}$. Cell viability (using the PicoGreen assay for dsDNA) and metabolic activity per live cell (using the luminescence assay) were measured, and no differences were observed when compared to the media controls (Figure 5).
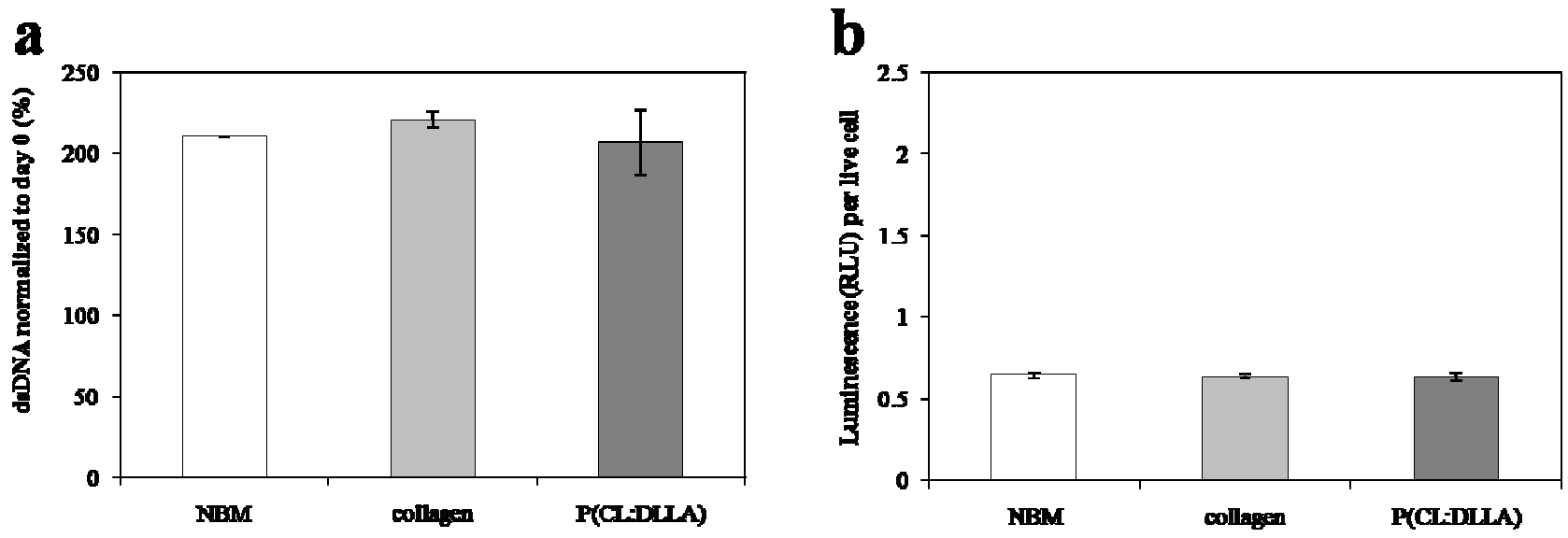

Figure 5: Electrospun fiber cytotoxicity study. NSPCs were cultured in fiber-conditioned media for 7 d. Both (a) PicoGreen: number of live cells, and (b) CellTiter Glo: cellular metabolic activity showed that the fibers were not cytotoxic to NSPCs.

\subsubsection{NSPC viability in fiber/HAMC composite}

Electrospun fibers were sonicated into small fragments and then dispersed in HAMC with NSPCs prior to injection through a 30G needle used for cell delivery. As shown in Figure 6, NSPCs were distributed throughout the HAMC and fiber/HAMC composite gels at both 2 and 7 days. At day 2, there was little difference between media controls (Fig 6a) and HAMC systems (Fig 6b, c, 
d); however, the NSPCs appeared to be in close contact with the electrospun collagen fibers (Fig $6 \mathrm{c}$, inset) and to extend their processes toward and adhere to the P(CL-co-DLLA) electrospun fibers (Fig 6d, inset). At day 7, cells suspended in media formed larger clusters due to cell aggregation and proliferation (Figure 6e) whereas NSPCs in the HAMC and fiber/HAMC composites remained more evenly distributed, forming smaller spheres and interacting with the fibers as at day 2 .

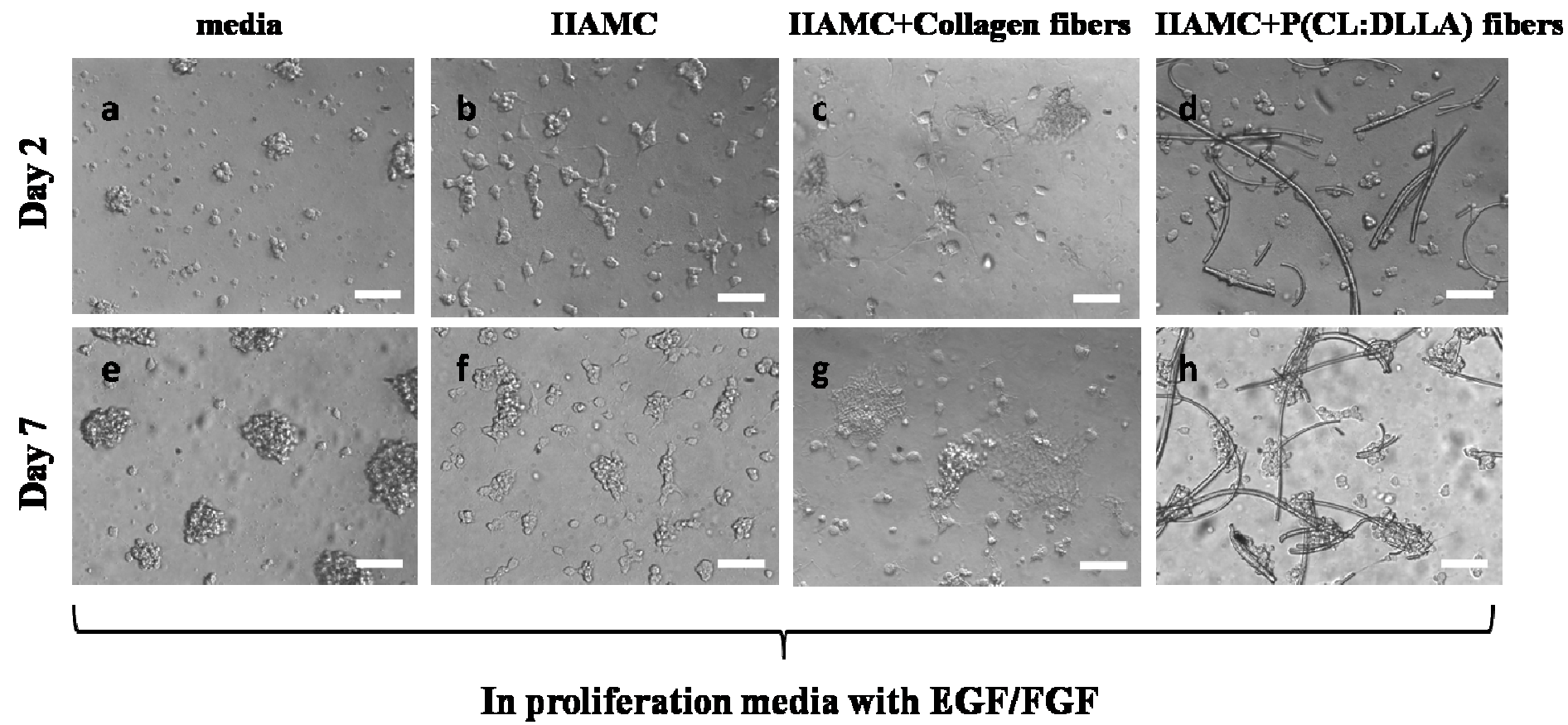

Figure 6: Bright-field microscopy of NSPCs seeded as single cells for 2 days (a-d) and 7 days (e-f) in: (a) and (e) media; (b) and (f) HAMC; (c) and (g) collagen/HAMC composite; and (d) and (h) $\mathrm{P}(\mathrm{CL}-\mathrm{co}-\mathrm{DLLA}) / \mathrm{HAMC}$ composite. Scale bar is $100 \mu \mathrm{m}$.

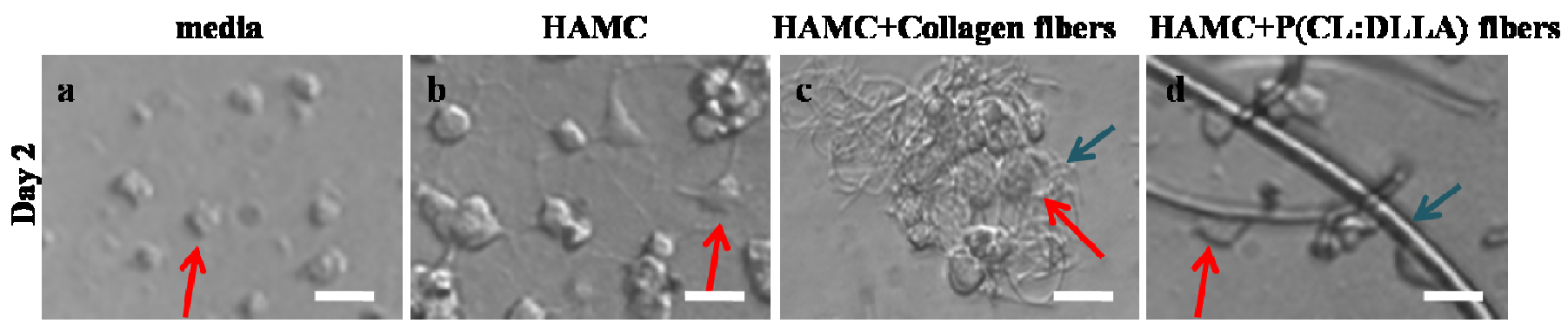

Figure 7: Bright-field images Figure $6 \mathrm{a}, \mathrm{b}, \mathrm{c}, \mathrm{d}$ zoomed in. Red arrows point to cells and blue arrows point to fibers. (a) Cell body stayed spherical. (b) Cell body enlargement, process extension, 
and network formation. (c) Collagen fibers surrounded NSPCs, and process extension was limited. (d) Cell processes iacted with P(CL:DLLA) fibers and adhered to fiber surface. Scale bar is $20 \mu \mathrm{m}$.

In the presence of collagen electrospun fibers, cells close in contact with the fibers had processes entangled with the fine fibers (Figure 7c). Although cell bodies were enlarged, processes were not able to extrude out. With P(CL:DLLA), NSPC had either extended their processes out to interact with fibers, or they migrated towards the fibers and adhered to the fiber surface if the cell and the fiber were in close proximity(Figure 7d). By day 7, NSPCs proliferated and migrated to junction points.

Cell viability was studied over 7 days using the PicoGreen assay for dsDNA (Figure 8). Importantly, cell viability was similar for all samples in each of the media conditions studied except the electrospun collagen/HAMC composite system where there were fewer viable cells in all media conditions than the other systems tested - media, HAMC and electrospun P(CL-co-DLLA)/HAMC composite. The data shown in Figure 5 suggested that neither collagen nor P(CL-co-DLLA) electrospun fibers released cytotoxic factors; thus, the decreased number of viable cells in the presence of collagen fibers suggests either a contact mediated mechanism or a high the local concentration of cytotoxic released factors.

\subsubsection{NSPC differentiation profile in fiber/HAMC composite}

The NSPC differentiation profile in the three media (NBM, 1\% FBS and EGF/FGF2) and the different matrices (Media, HAMC, electrospun collagen/HAMC, electrospun P(CL-coDLLA)/HAMC) was assessed using quantitative RT-PCR. The expression level of the gene of interest was evaluated against the house keeping gene, hypoxanthine phosphoribosyl transferase (HPRT) (Figure 8). The genes selected were: nestin for progenitor cells (Fig. 8a); $\beta$ III-tubulin for neurons (Fig. 8b), CNPase for oligodendrocytes (Fig. 8c), and GFAP for astrocytes (Fig. 8d). 
As shown in Figure 8a, NSPCs grown in all media and all matrices expressed the gene for nestin, with the highest expression found for cells in the proliferation media with EGF/FGF2. This is consistent with previous results where EGF/FGF2 mitogens promote proliferation of precursor cells vs. differentiation. In Figure 8b, the $\beta$ III-tubulin gene expression was similar across matrices in each media group and greatest for NSPCs cultured in NBM and 1\% FBS-supplemented media. Interestingly, the greatest $\beta$ III-tubulin gene expression was found for NSPCs cultured in NBM in $\mathrm{P}(\mathrm{CL}-\mathrm{co}-\mathrm{DLLA}) / \mathrm{HAMC}$ composite gels, suggesting that these materials have a greater influence on gene expression than the media. In contrast, the NSPCs cultured in NBM and $1 \%$ FBS in collagen fiber/HAMC composite gels had the lowest $\beta$ III-tubulin gene expression, confirming the importance of the extracellular environment. The $\beta$ III-tubulin gene expression was lowest for cells cultured in EGF/FGF2, as may have been expected for the proliferation medium. A similar trend was observed for CNPas gene expression (Figure 8c). NSPCs cultured in NMB and 1\% FBS in $\mathrm{P}(\mathrm{CL}-\mathrm{co}-\mathrm{DLLA})$ fiber/HAMC composite gels had the greatest CNPase gene expression whereas those cultured in collagen fiber/HAMC composite gels had the least. Again the EGF/FGF2 medium overwhelmed the CNPase gene expression and there was no difference across groups. The GFAP gene expression was influenced primarily by the medium (and not the matrix) as shown in Figure 8d, where the only differences observed, within one medium, were for the collagen fiber/HAMC composite system. Otherwise, the differences in GFAP gene expression were as expected, greatest in the differentiation, 1\% FBS medium and NBM and least in the proliferation EGF/FGF2 medium. 

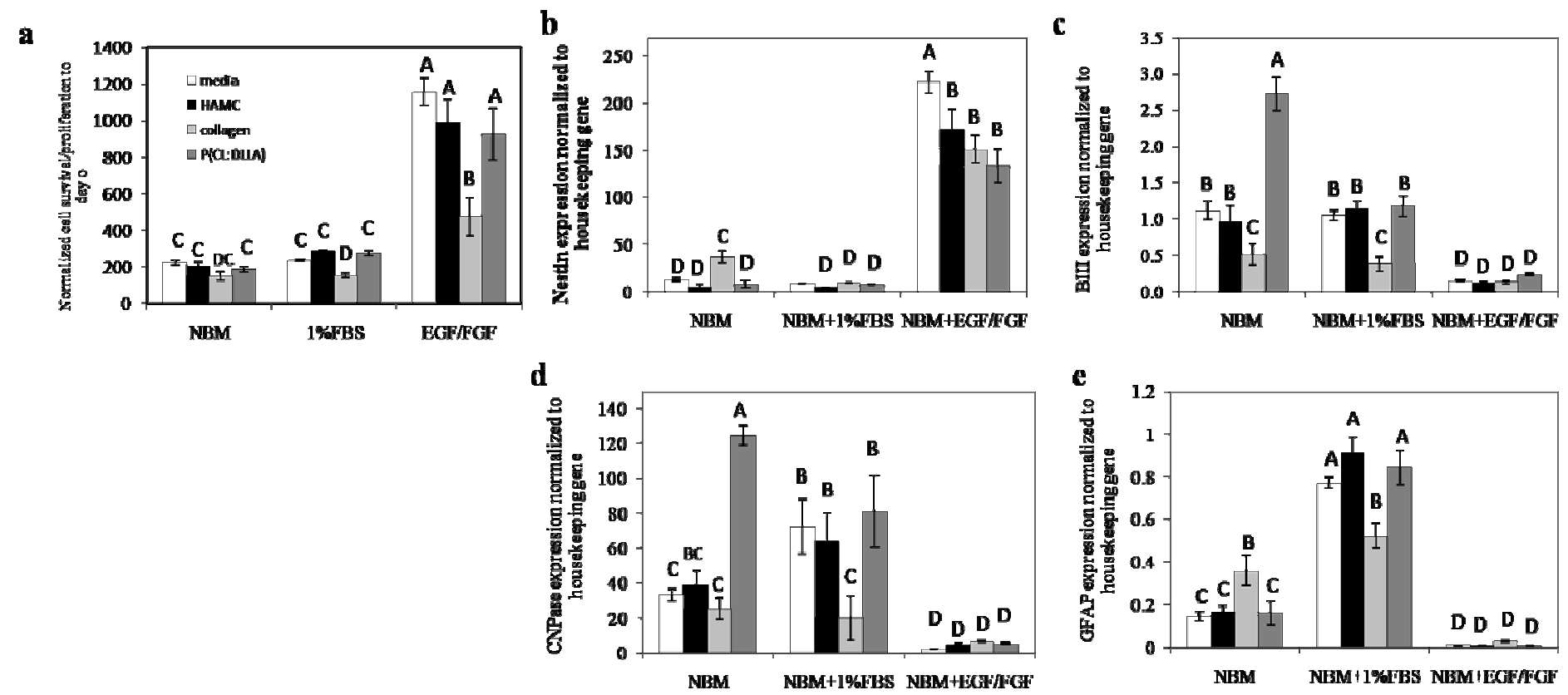

Figure 8: The gene expression profile at $7 \mathrm{~d}$ for NSPCs cultured in one of three media - serum-free neural basal media (NBM), differentiation media of NBM supplemented with 1\% FBS, proliferation media of NBM supplemented with EGF/FGF2 - and one of four matrices: media (control), HAMC, collagen fiber/HAMC composite, P(CL-co-DLLA) fiber/HAMC composite. The NSPCs were studied in terms of their gene expression profiles of (a) nestin for progenitor cells; (b) $\beta$ III-tubulin for neurons; (c) CNPas for oligodendrocytes; and (d) GFAP for astrocytes.

\section{DISCUSSION}

With the promises from NSPC therapy to spinal cord injuries, the limitation impeding an effective cell therapy is the survival and integration of the transplanted cell. The need for a microenvironment providing chemical or physical cues to direct cell behaviour has been recognized. Hence, it is our goal in this study to develop an injectable cell delivery vehicle and a microenvironment that would promote cell survival/proliferation and modulate cell behaviour, evaluated by delivering a viable cell population and a desirable cell differentiation profile with enhanced neuronal and oligodendrocytic differentiation. 
An injectable hydrogel allows for a minimally invasive cell delivery. Fast gelation of the thermal-reversible gel is defined in the condition that cells remain homogenously dispersed in the volume through the process. HAMC's shear-thinning and reverse-thermal gelation properties allow it to be injected through a fine needle at room temperature and to become a weak gel at physical temperature at $37^{\circ} \mathrm{C}$. Taking advantage of its minimal polymer weight percent required for hydrogel formation, the extent of HAMC swelling is greatly reduced, minimizing the risk of secondary compression to the injury site.

Implant materials considered to be biocompatible may not be suitable for cell delivery. Hence, cell compatible design criteria must be included and tested in developing a cell culture system. In addition to its high oxygen and nutrient permeability as a hydrogel, HAMC obtains the osmolarity of the media that makes up $99 \%$ of the volume, creating a good cell culture microenvironment. The concept of biocompatibility concerns not only the material but also the encapsulation process. HAMC's spontaneous gel formation/fabrication mechanism is gentle to NSPCs, with no involvement of organic solvents/cross-linkers or UV for chemical or photoinitiating crosslinking methods, respectively. Conventional cell seeding methodology including gravitational force, perfusion, 3D printing, or infiltration often require an incubation period and result in heterogeneous distribution and cell damage ${ }^{47}$. Therefore, mixing cells in HAMC is favourable for its simplicity and mild formulation conditions. The uniform viable cell dispersion in HAMC with high cell-seeding density and cell-survival efficiencies allows cell therapies to maximize its efficacy, especially when implanting micro volumes.

At high cell density, NSPCs have the tendency to aggregate which creates concentration gradient from the outer edge to the center, resulting in varying growth rate and nutrient consumption rates. Hence, when the size of neurospheres or cell aggregates exceed the critical 
mass, it leads to cell death due to limitation of nutrient, oxygen, and accumulation of metabolic waste, forming necrotic centers ${ }^{48,49}$. HAMC maintained even dispersion of NSPCs in 3D, minimized cell sedimentation and aggregation. This is further exemplified in proliferation media where cell density increased substantially over time, forming large cell aggregates in media leading to some cell death. Hence, HAMC minimizes cell death while keeping the cells in close proximity, maintaining a large percentage of viable cells within a population at high cell density.

The ability of the transplanted cell to interact with its surrounding and to become functional within an appropriate time frame is essential to an effective cell therapy. NSPCs responded quickly with morphological changes when dispersed in HAMC in contrast to suspended in media. The phenomenon could be potentially attributed to HAMC's mechanical and chemical properties mimicking CNS which minimized the lag time cells required to adjust to its new seeding environment. With processes extension and network formation, the functional NSPCs may be able to act to the hostile injured environment quickly. Cell grafts in vivo often experience heterogeneous cell responses from the core to the periphery. The graft close to the injured tissue would respond and integrate to the surrounding tissue, while the cells in the core of the graft remain quiescent ${ }^{50}$. The simultaneous commence of cell development throughout the graft encourage cells to navigate and interact with its niche collectively as a whole, with the potential to improve and to accelerate the bridging process.

HAMC is not toxic and it is cytocompatible to NSPCs. Conventional ATP assays were originally selected to assess cell viability; however, it was found that cellular metabolic activity depends on whether cells are proliferating or differentiating. Hence, the bulk ATP signal intensity cannot be used to compare cell viability across different media conditions. This indirect measurement is only effective and reproducible when used to determine numbers of viable cells in 
the same culture condition. A standard curve will need to be determined for each cell culture condition, with linearity and the slope of the curve to be tested and measured. Normalizing bulk ATP readings to the number of cells or dsDNA content yields information of how metabolic active each live cell is through the treatment. The inattentive use of the indirect measurement of viable cells by bulk ATP quantification could potentially give false positive results to cells at hypermetabolic state.

There is controversy in the literature as to whether cells have higher or lower metabolic activity at different cell states. Cho et al and Lonergan et al reported an increase of ATP content in human embryonic stem cells and stromal stem cells, respectively, when cells undergo greater differentiation ${ }^{51,52}$; whereas, Park et al found higher mitochondria metabolic activity when human corneal endothelial cells proliferate ${ }^{53}$. Since metabolic activity for different cell types/lines varies, this is the first report to examine ATP content of NSPCs at different states. It is found that NSPC has higher total plasma ATP content when proliferating. The intermediate ATP content per live cell between differentiation and proliferation states, obtained in NSPC dispersed in HAMC with proliferation media, (Figure 3b), may potentially represent a bulk average of a mixed population of NSPC at different states. Among these, the majority might be proliferating while some were induced to differentiate, as shown in by bright-field microscopic images and the differentiation profile.

In CNS regeneration by stem cell transplantation, the polymeric microenvironment acts as a template to promote cell adhesion, survival and to modulate cellular differentiation ${ }^{32}$. Electrospun fibers were incorporated in HAMC to provide substrates for direct cell-matrix interactions. Collagen scaffolds have been reported in literature to facilitate neural stem/progenitor cell transplantation and to promote recovery in the injured spinal $\operatorname{cord}^{54}$. And the biodegradable 
synthetic polymer, P(CL:DLLA), have been widely used as tissue-engineering scaffolds and shown biocompatible to NSPC ${ }^{55}$. Direct contact of cells with the fiber can reveal the effect of the cellmatrix interaction to cellular behaviour. Fine collagen fibers surrounding NSPCs have deleterious effects on cell survival/proliferation and functions. Whereas, P(CL:DLLA) sustained NSPC survival and guided cellular differentiation to the neuronal (functional unit in the CNS) and oligodendrocytic (supporting cell) lineages. It has been shown in literature that nanotopographical features including fiber diameter, surface morphology, as well as mechanical strength can alter cell behaviour $^{56-58}$. Hence, the distinct effects of collagen and P(CL:DLLA) to NSPCs may be attributed to several possible speculations: the fine and fragmented collagen fibers may be unable to sustain mechanical strength and to provide structural support when cells extended processes and apply tension, or the physical entrapping of NSPC in collagen fibers blocking processes extension. Nevertheless, P(CL:DLLA)'s beneficial effect to efficiently modulate NSPC differentiation profile towards desirable lineages without addition of growth factors should be further investigated and utilized.

In addition to cell-matrix interactions, soluble factors can also influence cell behaviour. In media containing $1 \% \mathrm{FBS}$, CNPase and GFAP gene expression were higher in contrast to basic media. The effect of serum to promote glial differentiation coincided with common practice in literature, where serum is used to sustain survival and to promote glial cell lineage ${ }^{59,60}$. 


\section{CONCLUSION}

Overall, we found that the cellular microenvironment is defined by the media and the hydrogel composite and each of these can influence the differentiation and proliferation profiles of NSPCs. The HAMC $0.5 / 0.5 \mathrm{w} / \mathrm{w} \%$ provided a facile hydrogel for stable cell distribution and delivery through an injectable delivery strategy. The inclusion of electrospun fibers in the hydrogel composite promoted cell survival and guided cell differentiation relative to media controls, demonstrating the importance of the microenvironment to cell behaviour. Of the two electrospun fibers examined, the $\mathrm{P}(\mathrm{CL}-\mathrm{co}-\mathrm{DLLA}) / \mathrm{HAMC}$ composite was most suitable for NSPC differentiation towards neuronal and oligodendrocytic phenotypes, the latter of which is important to myelination to either limit further degeneration or of regenerated axons. Future studies will evaluate these systems in vivo for NSPC survival and differentiation in established rodent SCI models. 


\section{RECOMMENDATIONS AND FUTURE DIRECTIONS}

Rodents' functional behaviour will be assessed to examine cell therapy efficacy with the help from a designed microenvironment. Further work can extend to include more integrative bioactive electrospun fibers for concurrent drug delivery or cell adhesive molecule immobilized sites. The versatility of HAMC hydrogel could serve as a platform for combinatory strategies, with the potential to lead to a clinically relevant and effective cell therapy.

The fast induction of NSPC response in HAMC in contrast to media controls observed at day 2 was not extended and translated to the gene expression profile at day 7. BIII-tubulin, CNPase, and GFAP expression in HAMC were comparable to media controls. At longer cell culture, NSPCs suspended in media had also started to differentiate, levelling out the initial burst of the number of cells that underwent differentiation. Further studies can look at the genes that are selectively expressed in more mature CNS cell types at day 7, or conduct the differentiation profile study at day 3 to reveal the differential effect. 


\section{Reference}

1. Hulsebosch CE. Recent advances in pathophysiology and treatment of spinal cord injury. Advances in Physiology Education 2002;26(4):238-255.

2. Gianvito Martino SP. The therapeutic potential of neural stem cells. Nature Reviews Neuroscience 2006;7(5):395-406.

3. Soheila Karimi-Abdolrezaee EE, Jian Wang, Cindi M. Morshead, Michael G. Fehlings. Delayed transplantation of adult neural precursor cells promotes remyelination and funcitonal neurological recovery after spinal cord injury. The Journal of Neuroscience 2006;26(13):3377-3389.

4. Ann M. Parr IK, Charles H. Tator. Transplantation of adult rat spinal cord stem/progenitor cells for spinal cord injury. Journal of Neurotrauma 2007;24(5):835-845.

5. Brian J. Cummings NU, Stanley J. Tamaki, Desiree L. Salazar, Mitra Hooshmand, Robert Summers, Fred H. Gage, Aileen J. Anderson. Human neural stem cells differentiate and promote locomotor recovery in spinal cord-injured mice. PNAS 2005;102(39):14069-14074.

6. Nic D. Leipzig MSS. The effect of substrate stiffness on adult neural stem cell behavior. Biomaterials 2009;30(36):6867-6878.

7. Feng Cao AHSR, Oscar J. Abilez, Haichang Wang, Jennifer T. Blundo, Beth Pruitt, Christopher Zarins, Joseph C. Wu. In vivo imaging and evaluation of different biomaterials for improvement of stem cell survival. Journal of Tissue Engineering and Regenerative Medicine 2007;1:465-468.

8. Gabriel A. Silva CC, Krista L. Niece, Elia Beniash, Daniel A. Harrington, John A. Kessler, Samuel I. Stupp. Selective differentiation of neural progenitor cells by high-epitope density nanofibers. Science 2004;303(5662):1352-1355.

9. Cushing MC. Hydrogel cell cultures. Science 2007;316(5828):1133-1134.

10. Mark W. Tibbitt kSA. Hydrogels as extracellular matrix mimics for 3D cell culture. Biotechnology and Bioengineering 2009;103(4):655-663.

11. Ying Luo MSS. A photolabile hydrogel for guided three-dimensional cell growth and migration. Nature Materials 2004;3:249-253.

12. Nic D. Leipzig CX, T. Zahir, Molly S. Shoichet. Functional immobilization of interferon-gamma induces neuronal differentiation of neural stem cells. Journal of Biomedical Materials Research. Part A 2009;online in advance of print.

13. Allison DD. Review. Hyaluronan: a powerful tissue engineering tool. Tissue Engineering 2006;12(8):2131-2140.

14. Sarkar N. Thermal gelation properties of methyl and hydroxypropyl methylcellulose. Journal of Applied Polymer Science 2003;24(4):1073-1087.

15. Matthew C. Tate DAS, Stuart W. Hoffman, Donald G. Stein, Michelle C. LaPlaca. Biocompatibility of methylcellulose-based constructs designed for intracerebral gelation following experimental traumatic brain injury. Biomaterials 2001;22:1113-1123.

16. F. Z. Cui WMT, S. P. Hou, Q. Y. Xu, I.-S. Lee. Hyaluronic acid hydrogel immobilized with RGD peptides for brain tissue engineering. Journal of Materials Science 2006;17(12):1393-1401.

17. W. M. Tian SPH, J. Ma, C. L. Zhang, Q. Y. Xu., I. S. Lee, H. D. Li, M. Spector, F. Z. Cui. Hyaluronic acidpoly-D-lysine-based three dimensional hydrogel for traumatic brain injury. Tissue Engineering 2005;11(3):513-525.

18. Dimpy Gupta CHT, Molly S. Shoichet. Fast-gelling injectable blend of hyaluronan and methylcellulose for intrathecal, localized delivery to the injured spinal cord. Biomaterials 2006;27(11):2370-2379.

19. Sandrine Thuret LDFM, Fred H. Gage. Therapeutic interventions after spinal cord injury. Nature Reviews Neuroscience 2006;7:628-643.

20. R. P. Bunge WRP, J. L. Becerra, A. Marcillo, R. M. Quencer. Observation on the pathology of human spinal cord injury. A review and classification of 22 new cases with detials from a case of chronic cord compression with extensive focal demyelination. Advances in Neurology 1993;59:75-89. 
21. Gregory D. Carlson CG. Current developments in spinal cord injury research. The Spine Journal 2002;2(2):116-128.

22. Kakulas BA. A review of the neuropathology of human spinal cord injury with emphasis on special features. The Journal of Spinal Cord medicine 1999;22:119-124.

23. Goldman S. Stem and progenitor cell-based therapy of the human central nervous system. Natural Biotechnology 2005;23(7):862-871.

24. Christine E. Schmidt JBL. Neural tissue engineering: strategies for repair and regeneration. Annual Review of Biomedical Engineering 2003;5:293-347.

25. Brent A. Reynold SW. Generation of neurons and astrocytes from isolated cells of the adult mammalian central nervous system. Science 1992;255(5052):1707-1710.

26. Rike Zietlow ELL, Stephen B. Dunnett, Anne E. Rosser. Human stem cells for CNS repair. Cell and Tissue Engineering 2008;331(1):301-322.

27. Hideyuki Okano MS, Koichi Ohki, Norihiro Suzuki, Kazunobu Sawamoto. Regeneration of the central nervous system using endogenous repair mechanisms. Journal of Neurochemistry 2007;102:14591465.

28. Maurice Vroemen LA, Juergen Winkler, Norbert Weidner. Adult neural progenitor cell grafts survive after acute spinal cord injury and integrate along axonal pathways. European Journal of Neuroscience 2003;18(4):743-751.

29. Y. Ogawa KS, T. Miyata, S. Miyao, M. Watanabe, Y. Toyama. Transplantation of in vitro expanded fetal neural progenitor cells results in neurogenesis and functional recovery after spinal cord contusion injury in rats. Jounal of Neuroscience Research 2002;69:925-933.

30. A. Hejcl PL, M. Pradny, J. Michalek, P. Jendelova, J. Stulik, E. Sykova. Biocompatible hydrogels in spinal cord injury repair. Physiological Research 2008;57:121-132.

31. Jason R. Thonhoff DIL, Paivi M. Jordan, Xu Zhao, Ping Wu. Compatibility of human fetal neural stem cells with hydrogel biomaterials in vitro. Brain Research 2007;1187(2):42-51.

32. Ana I. Teixeira JKD, Ola Hermanson. Getting the right stuff: controlling neural stem cell state and fate in vivo and in vitro with biomaterials. Cell Research 2007;17:56-61.

33. S. Gerecht JAB, L.S. Ferreira, S.A. Townsend, R. Langer, G. Vunjak-Novakovic. Hyaluronic acid hydrogel for controlled self-renewal and differentiation of human embryonic stem cells. Proceedings of the National Academy of Sciences 2007;104(27):11298-11303.

34. M. R. Wells SKK, D. K. Batter, D. G. Blunt, Z. J. Weremowitz, S. E. Lynch, H. N. Antoniades, H. A. Hansson. Gel matrix vehicle for growth factor application in nerve gap injuries repaired with tubes: a comparison of biomatrix, collagen, and methylcelluose. Experimental Neurology 1997;146:395402.

35. Dimpy Gupta CHT, Molly S. Shoichet. Fast-gelling injectable blend of HA and MC for intrathecal, localized delivery to the injured spinal cord. Biomaterials 2006;27(11):2370-2379.

36. A. Frenot ISC. Polymer nanofibers assembled by electrospinning. Current Opinion in Colloids and Interface Science 2003;8:64-75.

37. R. Kriparamanan PA, A. Zhou, K.T. Nguyen. Nanotechnology: cellular responses to nanostructured materials. Journal of Nanoscience and Nanotechnology 2006;6(7):1905-1919.

38. Z. M. Huang YZZ, M. Kotaki, S. Ramakrishna. A review on polymer nanofibers by electrospinning and their applications in nanocomposites. Composites Science and Technology 2003;63:2223-2253.

39. F. M. Pope ACN. Molecular abnormalities of collagen in human disease. Disease of Childhood 1987;62:523-528.

40. W. Ma WF, Q. Y. Liu. CNS stem and progenitor cell differentiation functional neuronal circuits in three dimensional collagen gels. Experimental Neurology 2004;190:276-288.

41. Wilfred F. A. Den Dunnen BvdL, Jeff M. Schakenraad, Engbert H. Blaauw, letse Stokroos, Albert J. Pennings, Peter $\mathrm{H}$. Robinson. Long-term evaluation of nerve regeneration in a biodegradable nerve guide. Microsurgery 1993;14(8):508-515. 
42. WFA den Dunnen IS, E.H. Blaauw, A. Holwerda, A. J. Pennings, P. H. Robinson, J. M. Schakenraad. Light-microscopic and electron-microscopic evaluation of short-term nerve regeneration using a biodegradable poly (DL-lactide-epsilon-caprolacton) nerve guide. Microsurgery 1996;14(8):508515.

43. G. Perego GDC, N. N. Aldini, M. Fini, R. Giardino. Preparation of a new nerve guide from a poly(Llactide-co-6-caprolactone). Biomaterials 2994;5:189-193.

44. Yan Su XL, Lianjiang Tan, Chen Huang, Xiumei Mo. Poly(I-lactide-co-caprolactone) electrospun nanofibers for encapsulating and sustained releasing proteins. Polymer 2009;50(17):4212-4219.

45. Daniel G. Anderson DP, Erin B. Lavik, Tahir A. Mahmood, Rober Langer. Biomaterial microarrays: rapid, microscale screening of polymer-cell interaction. Biomaterials 2005;26(23):4892-4897.

46. Eve C. Tsai PDD, Molly S. Shoichet, Charles H. Tator. Matrix inclusion within synthetic hydrogel guidance channels improves specific supraspinal and local axonal regeneration after complete spinal cord transection. Biomaterials 2006;27:519-533.

47. Luis A. Solchaga ET, Kitsie Penick, Harihara Baskaran, Victor M. Goldberg, Arnold I. Caplan, Jean F. Welter. A rapid seeding technique for the assembly of large cell/scaffold composite constructs. Tissue Engineering 2006;12(7):1851-1863.

48. Dustin R. Wakeman MRH, Yang D. Teng, Evan Y. Snyder. Neural Progenitors. Human Cell Culture 2009;7:1-44.

49. Alessandra Bez EC, Daniela Curti, Marco Biggiogera, Augusto Colombo, Roberto Francesco Nicosia, Stefano Filippo Pagano, Eugenio Agostino Parati. Neurosphere and nerosphere-forming cells: morphological and ultrastructural characterization. Brain Research 2003;993:18-29.

50. Ellen Bible DYSC, Morgan R. Alexander, Jack Price, Kevin M. Shakesheff, Michel Modo. The support of neural stem cells transplanted into stroke-induced brain cavities by PLGA particles. Biomaterials 2009;30:2985-2994.

51. Young Min Cho SK, Youngmi Kim Pak, Hye Won Seol, Young Min Choi, Do Joon Park, Kyong Soo Park, Hong Kyu Lee. Dynamic changes in mitochondrial biogenesis and antioxidant enzyme during the spontaneous differentiation of human embryonic stem cells. Biochemical and Biophysical Research 2006;348:1472-1478.

52. Thomas Lonergan CB, Barry Bavister. Differentiation-related changes in mitochondrial properties as indicators of stem cell competence. Journal of Cellular Physiology 2006;208:149-153.

53. Choul Yong Park ZZ, Cheng Zhang, Christina S. Moon, Roy S. Chunk. Cellular redox state predicts in vitro corneal endothelial cell proliferation capacity. Experimental Eye Research 2006;83:903-310.

54. M. Hatami NZM, S. Kiani, K. Hemmesi, H. Azizi, A. Shahverdi, H. Baharvand. Human embryonic stem-derived neural precursor transplants in collagen scaffolds promote recovery in injured rat spinal cord. Cytotherapy 2009:1-13.

55. Suk Ho Bhang JSL, Cha Yong Choi, Yunhee Kim Kwon, Byung-Soo Kim. The behavior of neural stem cells on biodegradable synthetic polymers. Journal of Biomaterials Science 2007;18(2):223-239.

56. Gregory T. Christopherson HS, Hai-Quan Mao. The influence of fiber diameter of electrospun substrates on neural stem cell differentiation and proliferation. Biomaterials 2009;30:556-564.

57. Joseph M. Corey CCG, Bor-Shuen Wang, Lisa K. Birrell, Sara L. Johnson, David C. Martin, Eva L. Feldman. The design of electrospun PLLA nanofiber scaffolds compatible with serum-free growth of primary motor and sensory neurons. Acta Bimaterialia 2008;4(4):863-875.

58. IL Keun Kwon KS, Matsuda Takehisa. Electrospun nano to microfiber fabrics made of biodegradable copolyesters: structural characteristics, mechanical properties and cell adhesion potential. Biomaterials 2005;26(18):3929-3939.

59. Malabendu Jana AJ, Utpal Pal, Kalipada Pahan. A simplified method for isolating highly purified neurons, oligodendrocytes astrocytes, and microglia from the same human fetal brian tissue. Neurochemical Research 2007;32(12):2015-2022. 
60. Bottenstein JE. Growth requirements in vitro of oligodendrocyte cell lines and neonatal rat brain oligodendrocytes. Proceedings of the National Academy of Sciences 1986;83(6):1955-1959. 